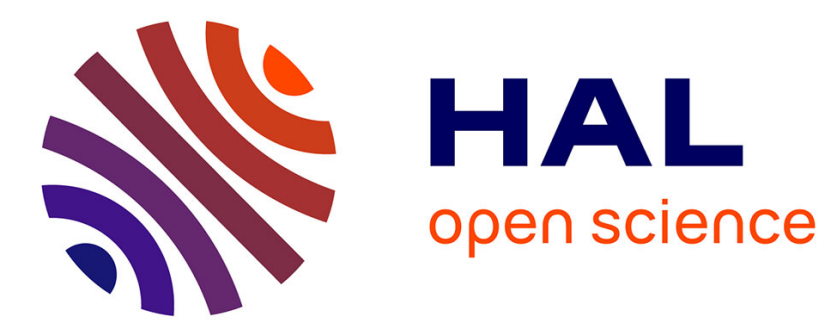

\title{
Agreeing with subjects in number: The rare split of Amuzgo verbal inflection
}

\author{
Enrique L. Palancar, Timothy Feist
}

\section{To cite this version:}

Enrique L. Palancar, Timothy Feist. Agreeing with subjects in number: The rare split of Amuzgo verbal inflection. Linguistic Typology, 2015, 93 (3), 10.1515/lingty-2015-0011 . hal-01247113

\section{HAL Id: hal-01247113 \\ https://hal.science/hal-01247113}

Submitted on 21 Dec 2015

HAL is a multi-disciplinary open access archive for the deposit and dissemination of scientific research documents, whether they are published or not. The documents may come from teaching and research institutions in France or abroad, or from public or private research centers.
L'archive ouverte pluridisciplinaire HAL, est destinée au dépôt et à la diffusion de documents scientifiques de niveau recherche, publiés ou non, émanant des établissements d'enseignement et de recherche français ou étrangers, des laboratoires publics ou privés. 


\title{
Agreeing with subjects in number: The rare split of Amuzgo verbal inflection
}

\author{
Enrique L. Palancar, Structure et Dynamique des Langues (UMR8292), CNRS \\ Timothy Feist, Surrey Morphology Group, University of Surrey
}

To appear in Linguistic Typology 19:3, 2015

\begin{abstract}
"[T]he formal expression of these categories involves a great deal of suppletion and morphologically conditioned internal modification and fusion, resulting in an extreme degree of irregularity. Indeed, Amuzgo morphology is so irregular that we have been tempted to call it a lexical language; that is, a language where the ideal seems to be for each form to have an idiosyncratic individuality rather than for it to be productively generatable [sic.]."
\end{abstract}

(Smith-Stark and Tapia, 1986)

\begin{abstract}
Verbs in San Pedro Amuzgo, an Oto-Manguean language of Mexico, often have two different stems in the paradigm, one used with singular subjects and the other with plural subjects. This constitutes a split motivated by number which is typologically interesting due to its rarity, since number splits are commonly only associated with the $\mathrm{S}$ and the $\mathrm{O}$ arguments, but not $\mathrm{S}$ and $\mathrm{A}$ as subject. Apart from at stem-level, the split is also manifested in the incompletive of an inflectional class of verbs. At stem-level the plural stem is derived in a variety of unproductive ways, making the relation between a singular stem and plural stem, synchronically, one of suppletion. In this paper, we study the distribution and the morphological properties of this split in depth, using a sample of almost 600 fully inflected verbs from a large database compiled by native linguist Fermín Tapia and now publicly accessible online at http://www.oto-manguean.surrey.ac.uk/ on the Surrey Morphology Group's website. We also place it in a typological context, relating it to other systems we have observed.
\end{abstract}

\section{Keywords}

Number split, inflection, agreement, Amuzgo, Oto-Manguean

\section{Introduction}

In this paper, we introduce a typologically rare case of number agreement that is found in the verbal inflection of San Pedro Amuzgo (henceforth SP Amuzgo), an Oto-Manguean language of Mexico. The paradigm of many verbs in this language displays a split, in other words, a division into two parts. The split is manifested in such a way that one of the portions of the paradigm is used when the verb agrees with a singular subject and the other when it agrees with a plural one. The phenomenon is illustrated in Table 1 with the past progressive subparadigm of the two verbs $m e P^{1}$ 'lie down' and $t s a ?^{1}$ 'hobble', where we use shading to distinguish the plural section of the subparadigm from the singular one (in the segmentation, the plus sign $(+)$ represents a stem formative: in this case the formative $n d i^{5}+$, found in the inflection of many verbs). ${ }^{2}$

\footnotetext{
${ }^{1} \mathrm{SP}$ Amuzgo is a tone language. There are eight contrastive tones, which are represented here with numbers: 1 being low. For more details see $\$ 2.2$.

${ }^{2}$ Abbreviations: CONT: continuous; COMP: complementizer; CPL: completive; DEM: demonstrative; DET: determiner; DU: dual; EXCL: exclusive; FUT: future; HON: honorific; HUM: human; INCL: inclusive; INCPL:
} 
Table 1. Two verbs with a subject number split in SP Amuzgo

\begin{tabular}{|c|c|c|}
\hline PST.PRG & 'lie down' & 'hobble' \\
\hline $1 \mathrm{SG}$ & to $^{3}-$ meP $^{1}=\mathrm{ha}^{3}$ & to $^{3}-$ ndi $^{5}+$ tsa $^{1}=$ ha $^{3}$ \\
\hline $2 \mathrm{SG}$ & to $^{3}-\mathrm{me}^{1}=? \mathrm{u}^{3}$ & to $^{3}-\mathrm{ndi}^{5}+\mathrm{tsa}^{1}=\mathrm{Pu}^{3}$ \\
\hline $3 \mathrm{SG}$ & $\mathrm{to}^{3}-\mathrm{me} \mathrm{P}^{1}=\tilde{\mathrm{e}}^{5}$ & to $^{3}-\mathrm{ndi}^{5}+\mathrm{tsa}^{1}=\tilde{\mathrm{e}}^{5}$ \\
\hline 1PL.INCL & to ${ }^{3}-$ toe $\tilde{P}^{3}=h^{5} a^{5}$ & to $^{3}-$ ndi $^{5}+$ ndaP $^{1}=$ ha $^{5} \mathrm{a}^{5}$ \\
\hline 1PL.EXCL & to $^{3}$-toẽ $P^{3}=h^{51}$ & to $^{3}-$ ndi $^{5}+$ ndaP $^{1}=$ ha $^{51}$ \\
\hline 2PL & to ${ }^{3}$-toe $\tilde{P}^{3}=? \mathrm{o}^{3}$ & to $^{3}-\mathrm{ndi}^{5}+\mathrm{ndaP}^{1}=\mathrm{Po}^{3}$ \\
\hline 3PL & to $^{3}$-to $\tilde{\mathrm{e}}^{3}=\tilde{\mathrm{e}}^{3}$ & to $^{3}-\mathrm{ndi}^{5}+\mathrm{ndaP}^{1}=\tilde{\mathrm{e}}^{3}$ \\
\hline
\end{tabular}

In Table 1, the split is manifested by the occurrence of two different stems for each verb: $m e P^{1}$ vs. toe $P^{3}$ for 'lie down' and $t s a P^{1}$ vs. $n d a P^{1}$ for 'hobble'. The selection of the stems responds to the presence of a singular or a plural subject, respectively. How shall we interpret this? One way to start is by taking a look at basic split types.

In a recent paper, Corbett (2015) proposes that splits in inflectional paradigms can be of two main types, labeled 'motivated' and 'morphomic'. The split in Amuzgo is an instance of a motivated one. Motivated splits respond to the existence of a natural class, commonly in the form of a coherent bundle of feature values from the syntax or the semantics, while morphomic ones do not. A typical example of a morphomic split is the suppletive pattern found in the present indicative of the French verb aller 'go' in Table 2. ${ }^{3}$ The split separates the portion of the paradigm for the 1st and 2nd person plural from the rest, but these person values do not form a natural class.

Table 2. The morphomic split of aller 'go' in French

\begin{tabular}{|c|c|}
\hline PRS.IND & 'go' \\
\hline $1 \mathrm{SG}$ & vais \\
\hline $2 \mathrm{SG}$ & vas \\
\hline $3 \mathrm{SG}$ & va \\
\hline $1 P L$ & allons \\
\hline $2 \mathrm{PL}$ & allez \\
\hline 3PL & vont \\
\hline
\end{tabular}

In contrast, motivated splits respond to natural classes, for example an aspect distinction as shown in Table 3 by the verb $b a^{2}$ štæ $^{2}$ 'wrap' in Chiquihuitlán Mazatec, another Oto-Manguean language, adapted from Jamieson (1982). The table shows the forms for the so-called neutral and the incompletive aspect.

incompletive; IND: indicative; IRR: irrealis; M: masculine; OBJ: object; PL: plural; PRF: perfect; PRG: progressive; PRO: pronoun; PRS: present; PST: past; RED: reduplication; SG: singular; SP: San Pedro Amuzgos; SUBJ: subject; SUBJV: subjunctive.

${ }^{3}$ A split of this kind is pervasive in Romance languages; for more details see Maiden (2005). 
Table 3. The motivated TAM split of $b a^{2} \check{S}^{2} z^{2}$ 'wrap' in Chiquihuitlán Mazatec

\begin{tabular}{|c|c|c|}
\hline \multirow{8}{*}{$\begin{array}{l}1 \mathrm{SG} \\
2 \mathrm{SG} \\
3 \\
1 \mathrm{PL} . \mathrm{INCL} \\
1 \mathrm{PL} . \mathrm{EXCL} \\
\text { 2PL }\end{array}$} & \multicolumn{2}{|c|}{ 'wrap’ } \\
\hline & NEUTRAL & INCPL \\
\hline & $\mathrm{ba}^{1} \check{s ̌ t}^{-} \mathfrak{x}^{1}$ & kua $^{1}$ št-æ ${ }^{1}$ \\
\hline & $\mathrm{ba}^{2} \check{\mathrm{s}} \mathrm{t}-\mathrm{e}^{2}$ & kua $^{2}$ št-e ${ }^{2}$ \\
\hline & $\mathrm{ba}^{2} \check{\mathrm{s}} \mathrm{t}-æ^{2}$ & kua $^{4}$ št-æ ${ }^{2}$ \\
\hline & $\mathrm{ba}^{2} \check{\mathrm{s} t}-\mathrm{e}^{2}$ & kua $^{2}$ št-ę ${ }^{2}$ \\
\hline & $\mathrm{ba}^{2} \mathrm{št}^{-\mathrm{i}_{\mathrm{t}}}{ }^{24}$ & kua $^{4}$ št $^{2} i^{24}$ \\
\hline & $\mathrm{ba}^{2} \check{s}^{2}-\mathrm{u}^{2}$ & $\mathrm{kua}^{2}$ št-ü ${ }^{2}$ \\
\hline
\end{tabular}

The split in SP Amuzgo in Table 1 treats the encoding of 1PL.INCL, 1PL.EXCL, 2PL and 3PL as a unified class by virtue of the fact they all share the value of plurality. This separation leaves the treatment of $1 \mathrm{SG}, 2 \mathrm{SG}$ and $3 \mathrm{SG}$ as a natural class too, sharing the value of singular. Because this separation is based on a number distinction grouping singular and plural forms as natural classes, this split is also an instance of a motivated split. This has consequences for the way in which we might interpret the syntax-morphology interface involving the number of the subject in Amuzgo morpho-syntax, because motivated splits are not like morphomic ones which only involve morphological patterns. As a consequence of the split, in order to inflect a verb in SP Amuzgo, it is necessary to first pay heed to the number of the subject in order to select the right stem $\{$ SG VS PL $\}$ and once this is done, attend to person-number values (and clusivity) as classes $\{1 \mathrm{SG}\}$ vs. $\{1 \mathrm{PL} . \mathrm{INCL}\}$, etc.

The split shown in Tale 1 is not something that occurs with only a couple of irregular verbs in SP Amuzgo, as is the case with the French verb aller, but rather it affects hundreds of verbs in its lexicon, so it is a defining characteristic of its inflection and thus of its morpho-syntax. On the formal level, the split has its intricacies because, although there are instances where the contrast between the two stems is achieved by a transparent morphological operation (albeit not a productive one), in most cases the relation between them is one of suppletion, at least synchronically. In light of this, the purpose of the paper is to present a detailed description of the factors that contribute to the singular-plural subject split in SP Amuzgo and to place it in a typological perspective in order to reveal what it can tell us about agreement patterns. To do this, a word about the language and the basics of its verbal inflection are in order.

\section{Amuzgo and its verbal inflection}

Amuzgo is a small language family from Mexico that belongs to the Oto-Manguean phylum. The family is thought to be composed of three languages (although a rigorous dialectal survey is still required to corroborate this): the language spoken in the state of Guerrero with its epicentre in the town of Xochistlahuaca (30,000 speakers); ${ }^{4}$ and two other languages in the state of Oaxaca: the language spoken in and around Santa María Ipalapa (900) and the language spoken in and around the village of San Pedro Amuzgos (6,500). We base our analysis on the San Pedro Amuzgos variety, located in Map 1, but the existing materials on Xochistlahuaca Amuzgo in Apóstol (2014) and Buck (2012) confirm that verbal inflection is very similar in structural terms, indicating that the phenomenon we study here should be taken to be a characteristic trait of Amuzgo as a family.

\footnotetext{
${ }^{4}$ Census by the INALI 2000
} 
Map 1. San Pedro Amuzgos, Oaxaca, Mexico.

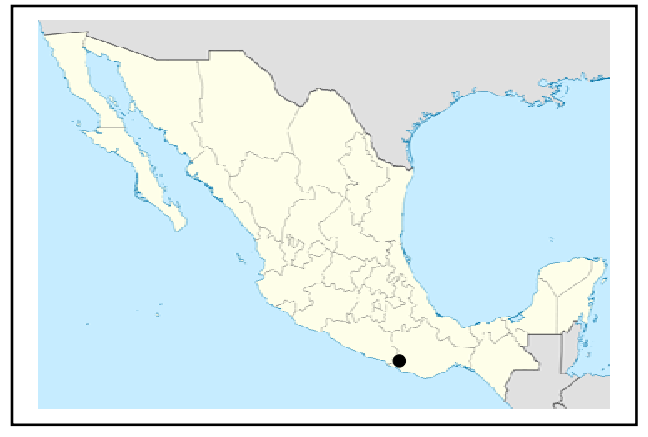

\subsection{Source of the data}

For our analysis, we use a sample of 579 verbs from the Amuzgo language of San Pedro Amuzgos, which we will refer to as SP Amuzgo. We sometimes refer to it just as 'Amuzgo' when the phenomenon under discussion is a trait of Amuzgo as a system and can be found in the other Amuzgo languages independently of differences in form.

The most important source of our data is the inflectional database compiled by the native linguist Fermín Tapia, which is publicly accessible online via the Surrey Morphology Group site at 〈http://www.oto-manguean.surrey.ac.uk〉. Fermín Tapia's complete database consists of about 500 inflected verbs. However, for the present purposes, we have only used 311 of them. The ones we include have been revised by Fermín Tapia together with linguist Yuni Kim from the University of Manchester. ${ }^{5}$ We have also left out a few compound verbs that show inflectional behavior identical to those of the simple verbs on which they are based.

Fermín Tapia's sample (henceforth FT) has an overwhelming number of intransitive verbs: only 35 out of the 311 verbs in our sample are transitive. To compensate for the lack of transitive verbs, in our sample we have also included another 268 transitive verbs from Stewart and Stewart's (2000) dictionary (henceforth S\&S), which are also available in the online database. We have excluded all transitive verbs in S\&S that were already present in FT's database, together with a couple of compounds which were inflectionally uninformative. It should be noted that the data in the two samples differ as to the type and scope of the inflectional information included, thus allowing us to use the two sources in different ways. The focus of the analysis is on FT's data because it is more complete: it gives all inflectional forms for every verbal entry. Every verb in SP Amuzgo has a paradigm consisting of 42 cells. This means that our analysis has been based primarily on the observation of 13,062 inflected forms. To complete the picture of Amuzgo verbal inflection we have also used data from Buck (2000), which served as the basis for the grammatical categorization of lexemes in the entries in S\&S. The figures in Table 4 provide a summary of how the verbs are distributed in our sample.

Table 4. Verbs in the sample

\begin{tabular}{|l|ll|l|}
\hline \multicolumn{1}{|c}{} & \multicolumn{1}{c}{ intr } & tr & Total \\
\cline { 2 - 4 } FT & 276 & 35 & 311 \\
S\&S & 0 & 268 & 268 \\
Total & 276 & 303 & 579 \\
\hline
\end{tabular}

\footnotetext{
${ }^{5}$ In the online database, unrevised verbal entries are indicated by two asterisks.
} 
With the addition of S\&S's data, the number of intransitive and transitive verbs in the sample is practically even. However, Amuzgo is an intransitive-oriented language; this means that the majority of basic verbs in the lexicon are intransitive, while the vast majority of the transitive verbs are causative verbs (60\% of the verbs in our sample), although the causative morphology they display is unproductive synchronically (see $\S 5.5$ for more details).

\subsection{Basics of the verbal inflection of Amuzgo}

In this section we introduce a few relevant characteristics of the verbal inflection of SP Amuzgo. This is done with the intention of creating a background for understanding what will follow. Verbs in Amuzgo inflect for TAM and for the person of the subject. As for TAM, verbs inflect for six values: incompletive, completive, past progressive, subjunctive, irrealis and future progressive. The TAM paradigm of the verb ndi ${ }^{5} t s \tilde{a} P^{3}$ ' $g o$ crazy' is given in Table 5. As a general rule, the marking of TAM is independent from that of person and number. To illustrate this, in Table 4 we give the forms for the 1st person singular alongside those of the 3rd persons singular and plural, which shows that there is no change affecting prefixal marking. We have set in boldface the prefixes marking TAM values.

Table 5. The TAM of the verb ndi ${ }^{5}$ tsã $P^{3}$ 'go crazy' in three persons

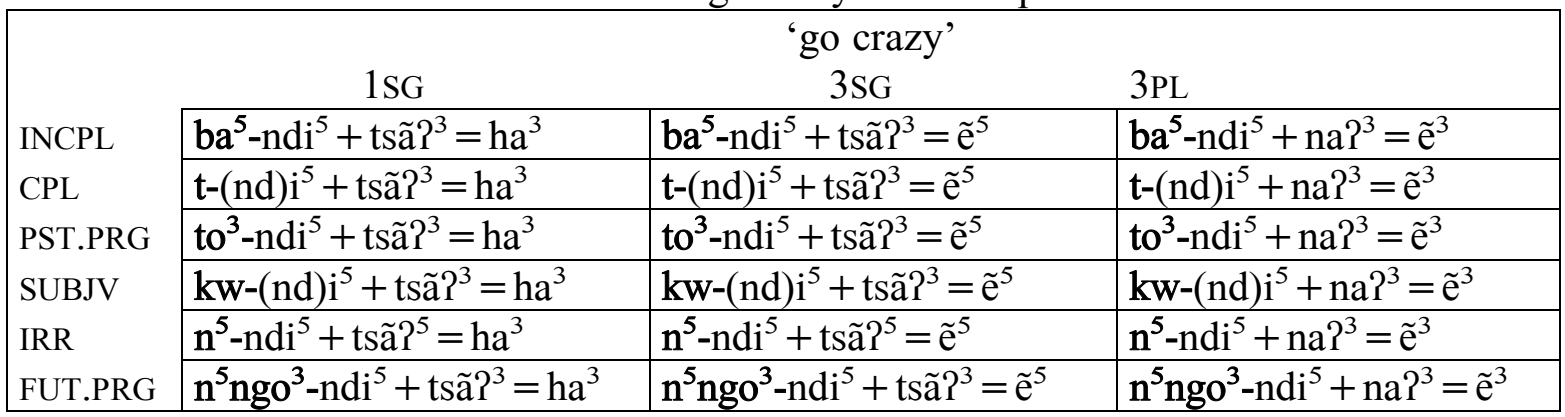

For the marking of the person of the subject, verbs fall into two classes that are called 'inactive' and 'active' in Smith-Stark and Tapia (1986, 2002). Members of the inactive class have a full set of segmental enclitics to mark person-number. All verbs given in the examples so far are inactive verbs. In contrast, for verbs belonging to the active class, the person of the subject is realized by a combination of tone patterns, glottalization patterns, and person suffixes. ${ }^{6}$ The two classes are illustrated in Table 6 with the incompletive forms of the verbs 'get upset' and 'get sick'. Notice that inactive verbs do not show variation in stem tone, while active verbs may and often do. $^{7}$ In Table 6 , we have also included the pronominal paradigm used for each class, following Smith-Stark and Tapia (2002). Shading is used for the values where the same form is used in both classes.

\footnotetext{
${ }^{6}$ A vowel marked as 〈V〉 represents an epenthetic copied vowel.

${ }^{7}$ The inactive verb 'get upset' also shows the number split we have presented in Table 1, while the verb 'get sick' is an example of a verb with glottalization (see further below).
} 
Table 6. Inactive/active intransitive verbs

\begin{tabular}{|c|c|c|c|c|c|}
\hline & $\begin{array}{l}\text { Inactive } \\
\text { 'get upset' }\end{array}$ & $\begin{array}{l}\text { Active } \\
\text { 'get sick' }\end{array}$ & Inactive & Active \\
\hline \multicolumn{2}{|c|}{$1 \mathrm{SG}$} & $\varnothing-x P \tilde{\mathrm{e}}^{5}=\mathrm{ha}^{3}$ & $\varnothing-b i^{12}$ & $=\mathrm{ha}^{3}$ & - \\
\hline \multicolumn{2}{|l|}{$2 \mathrm{SG}$} & $\varnothing-\mathrm{x} P \tilde{\mathrm{e}}^{5}=? \mathrm{u}^{3}$ & $\varnothing-b i(?)^{51}-?$ & $=? \mathrm{u}^{3}$ & $-?$ \\
\hline & HUM & $\varnothing-\mathrm{x} ? \tilde{\mathrm{e}}^{5}=\tilde{\mathrm{e}}^{5}$ & $\varnothing$-bi? ${ }^{12}=\mathrm{hu}^{5}$ & $=\tilde{\mathrm{e}}^{5}$ & $=\mathrm{hu}^{5}$ \\
\hline & $\mathrm{HON}$ & $\varnothing-x ? \tilde{\mathrm{e}}^{5}=\tilde{\mathrm{e}}^{3}$ & $\varnothing$-bi? ${ }^{12}=$ hõ $^{53}$ & $=\tilde{\mathrm{e}}^{3}$ & $=\mathrm{ho}^{53}$ \\
\hline & ANIMAL & $\emptyset-x \tilde{\mathrm{e}}^{5}=\mathrm{o} ?^{5} / \tilde{\mathrm{a}} \mathrm{P}^{5}$ & 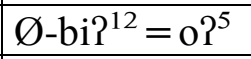 & $=o ?^{5} /=\tilde{a} 2^{5}$ & $=0 ?^{5}$ \\
\hline & INANIMATE & $\emptyset-x ? \tilde{e}^{5}=\tilde{a} 1^{1}$ & $\emptyset$-bi ${ }^{12}=\tilde{a} ?^{1}$ & $=\tilde{\mathrm{a}} \mathrm{P}^{1}$ & $=\tilde{a} 2^{1}$ \\
\hline \multirow{3}{*}{\multicolumn{2}{|c|}{$\begin{array}{l}\text { 1PL.INCL } \\
\text { 1PL.EXCL } \\
\text { 2PL }\end{array}$}} & $\emptyset$-nk? $\tilde{\mathrm{e}}^{5}=\mathrm{ha}^{5}\langle\mathrm{a}\rangle^{5}$ & $\varnothing-b \mathrm{i}^{12}\langle\mathrm{i}\rangle^{5}$ & $=\mathrm{ha}^{5}\langle\mathrm{a}\rangle^{5}$ & - \\
\hline & & $\varnothing$-nk? $\tilde{\mathrm{e}}^{5}=\mathrm{ha}^{51}$ & $\varnothing-b i^{51}$ & $=\mathrm{ha}^{51}$ & - \\
\hline & & $\varnothing$-nk? $\tilde{\mathrm{e}}^{5}=\mathrm{o} ?^{3}$ & $\varnothing-b i^{12}=o 1^{3}$ & $=0 ?^{3}$ & $=0 ?^{3}$ \\
\hline & HUM & $\varnothing-n k ? \tilde{\mathrm{e}}^{5}=\tilde{\mathrm{e}}^{3}$ & $\varnothing-b \mathrm{ii}^{12}=\mathrm{ho}^{5}$ & $=\tilde{\mathrm{e}}^{3}$ & $=\mathrm{ho}^{5}$ \\
\hline & $\mathrm{HON}$ & $\varnothing-n k ? \tilde{\mathrm{e}}^{5}=\tilde{\mathrm{a}}^{34}$ & $\varnothing$-bi? ${ }^{12}=\tilde{a}^{34}$ & $=\tilde{\mathrm{a}}^{34}$ & $=\tilde{a}^{34}$ \\
\hline
\end{tabular}

The inactive class consists almost entirely of intransitive verbs, while the active class contains both intransitive and transitive verbs. Taking into account intransitive verbs only, the two classes are distributed in our sample as indicated in Table 7. For convenience, we also include information about the intransitive verbs present in S\&S's dictionary but which are not considered in our sample.

Table 7. Distribution of inactive/active intransitive verbs

\begin{tabular}{|c|c|c|c|}
\hline & Inactive & Active & Total \\
\hline FT & 119 & 157 & 276 \\
\hline S\&S & 260 & 178 & 438 \\
\hline
\end{tabular}

Both classes have a semantic core. In other words, most of their members share a bundle of semantic properties typical of systems with semantic alignment (Mithun 1991, Donohue and Wichmann 2008, etc.). Within the active class (disregarding transitive verbs), one finds verbs referring to activities ( $\mathrm{kwa}^{3}$ 'eat', etc.), communication ( $2 \mathrm{ma}^{3}$ 'talk', etc.), manner of speaking ( $\mathrm{ta}^{3}$ 'sing', $\mathrm{tiu}^{1}$ 'whistle', etc.), locative motion verbs ( $\mathrm{wa}^{5} \mathrm{ka}^{5}$ 'walk', etc.), and posture and grooming verbs ( $w a^{35}$ 'lie down', $n^{5} d \varepsilon^{35}$ ? 'bathe', etc.). Within the inactive class we find verbs for natural phenomena ( $\mathrm{wa}^{1}$ ' rain', etc.), aspectual predicates ( $n d \varepsilon^{1}$ ' for something to finish', etc.), patient-oriented verbs (tyhe $2^{1}$ 'boil', $2 \tilde{o}^{5}$ 'sprout', to ${ }^{5}$ ' get filled up', etc.), inchoative verbs derived from adjectives ( $n d i^{5}+s i^{1}$ 'get wrinkled', $n d i^{5}+h \tilde{a}^{5}$ 'get dark', etc.), and so on. However, Smith-Stark and Tapia $(1986,2002)$ point out that despite such semantic alignment tendencies, membership of the classes is not predictable from the semantics because there are also verbs which pertain to one class but which would in principle be expected to belong to the other, i.e. the verbs bi ${ }^{12}$ 'get sick' in Table $6, h m e P^{34}$

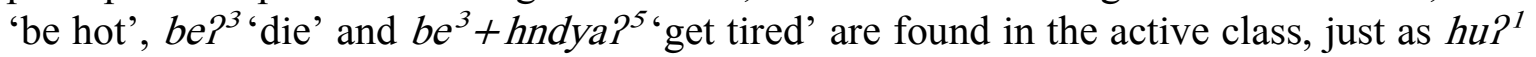
'jump' and other causative based verbs such as $t s i^{5}+n t h a P^{53}$ 'quarrel' and $t s i^{5}+t i u^{1}$ 'call somebody by whistling' (from the active verb tiu "whistle') are members of the inactive class. This lack of predictability suggests that the most suitable analysis of the classes is in terms of inflectional classes rather than just semantic classes. A similar position has been argued convincingly by Apóstol (2014) for the counterpart classes in the Amuzgo language of Xochistlahuaca. 
As we will see further below, the distinction between inactive and active verbs is relevant for the split we are studying. Active verbs have intricate morphology. For example, they use tone as a marker of person of the subject. As for tone, SP Amuzgo has eight tones involved in lexical contrasts (some of which are also found in verbal inflection). Following Smith-Stark and Tapia's $(1986,2000)$ notation, we represent tone using numbers. In the scale, number ' 1 ' represents low tone and ' 5 ' represents high tone. The minimal octuplet in Table 8 is from Kim (in press) illustrate the eight tones. ${ }^{8}$

Table 8. The eight tones of SP Amuzgo

\begin{tabular}{|lll|}
\hline \multicolumn{2}{|l|}{ Kim (in press) } & Buck (2000) \\
$\mathrm{n}_{0} \varepsilon^{1}$ & 'grass' & $\mathrm{L}$ \\
$\mathrm{n}_{0} \varepsilon^{12}$ & 'vegetation' & $\mathrm{LL}$ \\
$\mathrm{n}_{\circ} \varepsilon^{3}$ & 'cheap' & $\mathrm{M}$ \\
$\mathrm{n}_{\circ} \varepsilon^{34}$ & 'shudder.CPL.3SG' & $\mathrm{MM}$ \\
$\mathrm{n} \varepsilon^{35}$ & 'ripe' & $\mathrm{MH}$ \\
$\mathrm{n}_{0} \varepsilon^{5}$ & 'dust' & $\mathrm{H}$ \\
$\mathrm{n}_{0} \varepsilon^{51}$ & 'already' & $\mathrm{HL}$ \\
$\mathrm{n} \varepsilon^{53}$ & 'sell.CPL.1SG' & $\mathrm{HM}$ \\
\hline
\end{tabular}

In the octuplet in Table 8 , the words with tones $/ 34 /$ and $/ 53 /$ are inflected forms for the completive of $3 \mathrm{rd}$ person and 1st person, respectively. We treat the tone pattern in $3 \mathrm{rd}$ person forms, singular or plural, as representing lexical tone. The 2 nd person plural form always has the same tone as the 3rd person plural, while the 1st person plural exclusive is always marked by $/ 51 /$. For the marking of the remaining three person values (i.e. 1 st person singular, 2nd person singular and 1st person plural inclusive), there is tonal allomorphy across the different paradigms. Such allomorphy can be seen as dividing the lexicon into tone classes whose membership is dictated by the lexicon (for details see Kim, in press).

Apart from tone, most verbs whose stems end in /e/ or /o/ also undergo vowel lowering to $/ \varepsilon /$ and $/ \mathrm{s}$, respectively, in the 1 st person singular and 1 st person plural inclusive. In the realization of the 1st person plural inclusive, there is often an echo vowel as well, which can be seen for example in the form $b 2 i^{12}\langle i\rangle^{5}$ 'we (INCL) get sick' in Table 6, contrasting with $b ? i^{51}$ 'we (EXCL) get sick' without an echo vowel and with a different tone.

Glottalization is yet another important parameter in the building of inflectional paradigms for SP Amuzgo. While the 2nd person singular is always marked with a suffixed -2 , there is at times a high degree of stem allomorphy involving glottalization patterns which Kim (to appear) proposes to organize into five morphophonological classes. For example, the verb bi ${ }^{12}$ 'get sick' in Table 6 has two different stems involving a glottal: /C?V/ and /CV?/. For the glottalization class to which this verb belongs, $/ \mathrm{C} ? \mathrm{~V} /$ is used for the 1 st person singular and all persons in the plural, while /CV?/ is used for both the 2nd and the 3rd person singular. ${ }^{9}$

\footnotetext{
${ }^{8}$ In Table 8, we follow Kim's (to appear) treatment of tone /31/ in FT's database as /51/, following Buck's (2000) treatment of the same tone as /HIGH-LOW/.

${ }^{9}$ Suffixing $-?$ for the 2 nd person to a stem that already bears a glottal in the coda like /CV?/ results in the elision of one of the glottals.
} 
Having presented the basics of Amuzgo verbal inflection, we are now in a position to consider the number split in greater depth. We begin by presenting the general characteristics of this split and then go on to investigate the way it is realized by the morphology.

\section{The number split in Amuzgo: singular vs. plural subject}

As we have seen in Table 1, a verb in SP Amuzgo may present a split in its paradigm between the forms that index a singular subject and those that index a plural one. The split only involves the number of the subject, i.e. it is insensitive to the number of the object. The association with the subject is shown in examples (1) and (2) with the two different stems of the transitive verb ?wa ${ }^{1}$ 'cut with a machete'. Examples are from Buck (2000: 52, 72), but glosses, tones, the modified orthography and the translation are our own. Example

(2) additionally shows that the language has a VSO word order.

(1) ti $^{5}$ kiu? $^{12} \quad \operatorname{ta}^{3}$ a.while.ago CPL.start[3SG] boy-small ${ }_{i}=$ DET.SG

$$
\mathrm{na}^{3} \quad \mathrm{i}^{5}-\mathrm{waa}^{1}=\mathrm{hu}^{5} \quad\left[\mathrm{ndu}^{1}\right]_{\mathrm{OBJ} . \mathrm{SG}}
$$

COMP 3SG.INCPL-cut.SG[3SG]= PRO3SG.HUM ${ }_{i}$ wood

'The boy started cutting wood a while ago.'

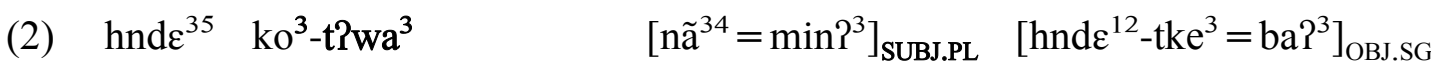
already PL.INCPL-cut.PL[3PL] people $=$ DEM.PL woodland-old $=$ DEM.SG 'Those people are already clearing out (i.e. cutting) this old woodland.'

These examples show that a different stem of the verb is required when the subject is singular than when it is plural, i.e. - ?wa ${ }^{1}$ is used in (1) for a singular subject (note that the two clauses in (1) have the same subject; the pronominal clitic $=h u^{5}$ in the subordinated clause cross-references the NP referring to the 'boy' in the main clause) and - $t$ ? $w a^{3}$ is used in (2) for a plural subject. The crucial thing is that in both clauses the object remains invariably singular, which provides evidence that the different stems reflect the number of the subject and not that of the object. As the split in Amuzgo is concerned with number and it involves verbs, it could be taken to be an instance of verbal number, but in reality it is not, as we argue in the next section.

\subsection{Verbal number typologically and in Amuzgo}

The study of verbal number has received recent attention in linguistic typology given the diversity of grammatical and lexical constructions involving plurality and verbs across languages (for a recent comprehensive review, see for example Cabredo Hofherr, 2010, and Cabredo Hofherr and Laca, 2012). 'Verbal number' is commonly used as an umbrella term to cover verbal constructions elaborating on either the repetition or the multiplicity of events or the plurality of affected participants in events. Following Corbett's (2000) taxonomy of verbal number, the first type is commonly treated as 'event number' and the markers involved in its encoding are known as 'pluractionals', ${ }^{10}$ while the second type is known as 'participant number'. The number split of Amuzgo is different from both of these, as we will show next.

\footnotetext{
${ }^{10}$ The term 'pluractional' is from Newman (1980) where it describes a particular class of derived verb stems in Chadic languages, as in example (4) from Hausa. In the languages of the Americas, pluractionals are also found. See for example Henderson (2012) for the Mayan languages and Gillon and Mailhammer (2015) for Yuman.
} 
Event number is illustrated by the contrasting examples in Hausa presented in (3) and (4), cited in Corbett (2000: 246) from Eulenberg (1971: 73-4), with glossing inspired by Caron (2012) and tones added courtesy of Bernard Caron (p.c.). ${ }^{11}$

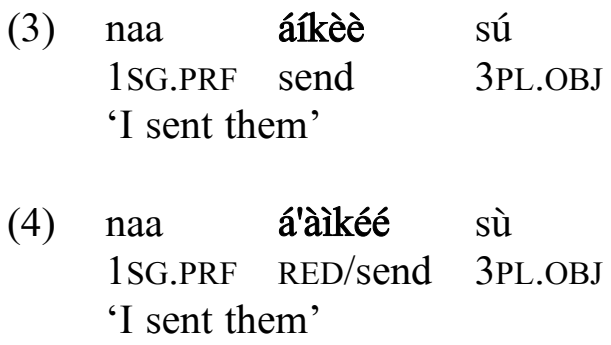

In contrast to (3), the verb aikaa 'send' appears in (4) in a reduplicated form which expresses plurality of actions. Both examples mean 'I sent them', both involve a plural object, and both can be used for a variety of event situations, e.g. the sending was at the same time to different places, at different times to the same place or at different times to different places. However, only (3) can be used for a situation where the sending was at the same time to the same place for which (4) is ungrammatical. This restriction means that the reduplicating construction in (4) is only used when there is some multiplicity of acts of sending (whether in the initial stages, i.e. the packaging, or in the final stages, i.e. the delivering).

Participant number, meanwhile, involves plurality of participants and often comes in the form of verbal suppletion. This is illustrated in Hiw, an Oceanic non-Polynesian language of Vanuatu, in the lexical contrast between (5) and (6), from François (2009).
(5) nine sō (*nine iw)
3SG fall.SG
'S/he fell.'
(6) sise iw $\quad(*$ sise sō)
3PL fall.PL
'They fell.'

Participant number as found in Hiw bears a strong resemblance to the split we observe in Amuzgo verbs, but it is different. In languages with typical participant number, like Hiw, the selection of a verb in a number pair (or of the relevant plural or dual inflection) responds to the number of the subject with intransitive verbs, but to the number of the object with transitive verbs. This is shown in the transitive pair in (7) and (8), also from Hiw (François, 2009).
(7) temarërë peon not $\left[\begin{array}{ll}\mathrm{i} & \text { noke }\end{array}\right]_{\mathrm{OBJ.SG}}$ old.man FUT kill.SG OBJ 1SG
'The ogre is going to kill me!'

\footnotetext{
${ }^{11}$ The transitive verb is inflected in Grade 4 indicating that the action is finished and the object is fully affected.
} 
$\begin{array}{llll}\text { (8) temāërë } & \text { peon qētñog } & {[\mathrm{i}} & \text { tite }]_{\text {oB..PL }} \\ \text { old.man } & \text { FUT kill.PL } & \text { OBJ 1PL.INCL }\end{array}$

'The ogre is going to kill us!'

This pattern of alignment is accounted for by thinking of both $\mathrm{S}$ and $\mathrm{O}$ as the most affected actants in the dynamism of the event encoded by the verb, while the A actanct would remain a non-affected, external participant. Participant number, as present in Hiw, is well-documented in the Polynesian and the Uto-Aztecan language families, but it is also found in many other languages with a more sporadic distribution. for example in isolate Ainu (Tamura 1988), in Koasati (Muskogean) (Mithun 2001), and in Shipibo-Conibo (Valenzuela 1997).

In languages with participant number, the phenomenon involves a restricted set of lexical pairs which rarely amounts to more than $30 .{ }^{12}$ Within the Oto-Manguean phylum to which Amuzgo belongs, we also find participant number. In Lealao Chinantec, possibly the Oto-Manguean language with the greatest number of such pairs. the list amounts to 12 pairs (at least considering the data in the dictionary in Rupp and de Rupp. 1996). In SP Amuzgo. participant number is restricted to the three pairs in (a-c) in Table 9. i.e. it only involves six transitive verbs in the language in total, and the list is exhaustive. Notice that the six verbs in Table 9 also displav the split involving number of the subiect. This is strong evidence that the two splits represent two different and mutually independent phenomena.

Table 9. The six verbs with participant number in SP Amuzgo

\begin{tabular}{|c|c|c|c|}
\hline \multirow{3}{*}{ a. } & SG.SUBJ & PL.SUBJ & \multirow{3}{*}{$\begin{array}{l}\text { 'kill (SG.OBJ)' } \\
\text { 'kill (PL.OBJ)' }\end{array}$} \\
\hline & tskwe? $^{5}$ & nã ${ }^{1}{ }^{k w e} ?^{5}$ & \\
\hline & tskwhe $^{5}$ & nã $1^{1} \mathrm{kwhe}^{5}$ & \\
\hline \multirow[t]{2}{*}{ b. } & $\mathrm{bPa}^{3}$ & $\mathrm{tPa}^{12}$ & 'grab (SG.OBJ)' \\
\hline & $\mathrm{bha}^{3}$ & tha $^{12}$ & 'grab (PL.OBJ)' \\
\hline \multirow[t]{2}{*}{ c. } & $\mathrm{y} 2 \tilde{o}^{35}$ & y? $\tilde{o}^{1}$ & 'take (SG.OBJ)' \\
\hline & $\mathrm{chu}^{5}$ & cho $^{1}$ & 'take (PL.OBJ)' \\
\hline
\end{tabular}

\subsection{The distribution of the number split of Amuzgo}

Although in the split the selection of the two morphological forms (i.e. the two stems) is triggered by the syntax (i.e. a rule of subject agreement in number), not all verbs display it. To illustrate this, compare the four active verbs in Table 10.

Table 10. Verbs with and without the number split

\begin{tabular}{|c|c|c|c|c|}
\hline CPL & 'smash' & 'grow old' & 'know, feel' & 'chew' \\
\hline $1 \mathrm{SG}$ & $\operatorname{nchh}\langle\varepsilon\rangle^{53}$ & $\mathrm{t}-(\mathrm{nd}) \mathrm{i}^{5}+\mathrm{xk}(\varepsilon)^{3}$ & $\mathrm{t}-(\mathrm{nd}) \mathrm{i}^{5}+\mathrm{nchhi}^{53}$ & $x P u\langle\varepsilon\rangle^{53}$ \\
\hline $2 \mathrm{SG}$ & nchhe $^{3}-?$ & $\mathrm{t}-(\mathrm{nd}) \mathrm{i}^{5}+\mathrm{xke^{3 } - ?}$ & $\mathrm{t}-(\mathrm{nd}) \mathrm{i}^{5}+\mathrm{nchhi}^{53}-?$ & xiue ${ }^{53}-?$ \\
\hline $3 \mathrm{SG}$ & nchhe ${ }^{3}$ & $\mathrm{t}-(\mathrm{nd}) \mathrm{i}^{5}+\mathrm{xke}^{3}$ & $\mathrm{t}-(\mathrm{nd}) \mathrm{i}^{5}+\mathrm{nchhi}^{35}$ & $x ? u e^{35}$ \\
\hline 1PL.INCL & $\operatorname{nchh}\langle\varepsilon\rangle^{34}$ & $\mathrm{t}-(\mathrm{nd}) \mathrm{i}^{5}+\mathrm{xk}\langle\varepsilon\rangle^{34}$ & $t-($ nd $) i^{5}+$ ngi \langle\rangle$^{12}$ & hndy?u $\langle\varepsilon\rangle^{35}\langle\varepsilon\rangle^{5}$ \\
\hline 1PL.EXCL & nchhe $\mathrm{s}^{51}$ & $\mathrm{t}-(\mathrm{nd}) \mathrm{i}^{5}+\mathrm{xke^{51 }}$ & $\mathrm{t}-(\mathrm{nd}) \mathrm{i}^{5}+$ ngio $^{51}$ & hndy?ue 51 \\
\hline $2 \mathrm{PL}$ & nchhe $^{3}=o ?^{3}$ & $\mathrm{t}-(\mathrm{nd}) \mathrm{i}^{5}+\mathrm{xke^{3 }}=\mathrm{o} \mathrm{P}^{3}$ & $\mathrm{t}-(\mathrm{nd}) \mathrm{i}^{5}+$ ngio $^{1}=\mathrm{oP}^{3}$ & hndy?ue ${ }^{35}=\mathrm{oP}^{3}$ \\
\hline 3PL & $\operatorname{nchhe}^{3}\left(=\right.$ ho $\left.^{5}\right)$ & $\mathrm{t}-(\mathrm{nd}) \mathrm{i}^{5}+\mathrm{xke}^{3}\left(=\mathrm{ho}^{5}\right)$ & $\mathrm{t}-(\mathrm{nd}) \mathrm{i}^{5}+\operatorname{ngio}^{1}\left(=\mathrm{ho}^{5}\right)$ & hndy?ue ${ }^{35}\left(=\right.$ ho $\left.^{5}\right)$ \\
\hline
\end{tabular}

${ }^{12}$ Commonly, the verbs in question mainly involve motion, location and a few highly manipulative actions. 
As shown in Table 10, the verbs $n c h h e^{3}$ 'smash' and $x k e^{3}$ '(for a woman to) grow old' have invariant stems throughout their paradigms. This contrasts with the suppletion we find for verbs $n c h h i^{53} \sim n g i o^{1}$ 'know' and $x$ ? $u e^{35} \sim h n d y ? u e^{355}$ 'chew'. The distribution of the number split in our sample of 579 verbs is given in Table 11, where we show that almost $70 \%$ of the verbs in the sample manifest the split in some way or another.

Table 11. Distribution of the split in the sample

\begin{tabular}{|lll|}
\hline $\begin{array}{l}\text { SG-PL } \\
\text { split }\end{array}$ & $\begin{array}{l}\text { No } \\
\text { split }\end{array}$ & Total \\
\hline 393 & 186 & 579 \\
$68 \%$ & $32 \%$ & $100 \%$ \\
\hline
\end{tabular}

Whether or not a verb will display the split is not predictable. We only find tendencies. For example, the split is typically associated with active verbs. This is shown in Table 12a, where more than $95 \%$ of the verbs with the split are active. However, Table $12 \mathrm{~b}$ shows that this does not mean that all active verbs have the split: almost $20 \%$ of them do not.

Similarly, while $85 \%$ of the inactive verbs do NOT exhibit a split, we still have 18 verbs in the sample that do. These tendencies suggest that the split is linked to the division of verbs into inactive and active classes, but still somehow independent from it.

Table 12. The distribution of the number split across inactive/active verbs.

\begin{tabular}{|l|ll|ll|}
\hline \multirow{2}{*}{$\begin{array}{l}\text { a. } \\
\text { Active }\end{array}$} & \multicolumn{2}{l|}{ SG-PL split } & \multicolumn{2}{l|}{ No split } \\
\cline { 2 - 5 } Inactive & 375 & $95.5 \%$ & 84 & $45 \%$ \\
\hdashline Total & 18 & $4.5 \%$ & 102 & $55 \%$ \\
\hline b. & 393 & $100 \%$ & 186 & $100 \%$ \\
SG-PL split & \multicolumn{2}{|l|}{ Active } & \multicolumn{3}{|c|}{ Inactive } \\
\cline { 2 - 5 } No split & 875 & $81.5 \%$ & 18 & $15 \%$ \\
\hdashline Total & 84 & $18.5 \%$ & 102 & $85 \%$ \\
\hline
\end{tabular}

The number split also shows a relevant correlation with transitivity: $98 \%$ of transitive verbs have the split, whereas it is only observed in $35 \%$ of intransitive verbs.

Table 13. The distribution of the number split in relation to transitivity.

\begin{tabular}{|l|ll|ll|}
\hline \multicolumn{1}{c}{} & \multicolumn{1}{c|}{$\operatorname{tr}$} & \multicolumn{3}{c|}{ intr } \\
\cline { 2 - 5 } SG-PL split & 296 & $98 \%$ & 97 & $35 \%$ \\
No split & 7 & $2 \%$ & 179 & $65 \%$ \\
\hline Total & 303 & $100 \%$ & 276 & $100 \%$ \\
\hline
\end{tabular}

We may look at the same data from a different point of view, but we obtain similar results. This is shown in Table 14, where we can see that three quarters of the verbs that display the split are transitive (i.e. 296 verbs out of 393), while $96 \%$ of the ones that do not are intransitive (179 out of 186). The fact that the split is strongly associated with transitive verbs equally shows that we are dealing with a very different phenomenon to participant number. 
Table 14. The distribution of transitivity in relation to the number split.

\begin{tabular}{|c|c|c|c|c|}
\hline \multirow{3}{*}{$\begin{array}{l}\text { tr } \\
\text { intr }\end{array}$} & \multicolumn{2}{|c|}{ SG-PL split } & \multicolumn{2}{|c|}{ No split } \\
\hline & 296 & $75 \%$ & 7 & $4 \%$ \\
\hline & 97 & $25 \%$ & 179 & $96 \%$ \\
\hline Total & 393 & $100 \%$ & 186 & $100 \%$ \\
\hline
\end{tabular}

\subsection{Domains where the number split is observed}

The split as such may be observed in two different domains: (i) in the domain of the marking of TAM, where it is found in the encoding of the incompletive within a particular class of verbs; and (ii) in the domain of the verbal stem, where it is exploited in various ways, as we will show in detail in $\S 5$ below. All examples given so far that show the split (in Tables 1, 6 and 10) are instances of stem-based splits. While the two domains work independently of each other, when all verbs are taken into account almost $80 \%$ of them display the singular-plural split twice, i.e. in both domains (examples of a doubly-marked split are given in Table 22, 25 and 53 below). This is shown in Table 15.

Table 15. Verbs according to the type of their number split.

\begin{tabular}{|lll|}
\hline TAM-based split only & 33 & $8.5 \%$ \\
Stem-based split only & 55 & $14.0 \%$ \\
Both TAM-based \& stem-based & 305 & $77.5 \%$ \\
\hline Total & 393 & $100 \%$ \\
\hline
\end{tabular}

When transitivity is factored in, however, transitive verbs have an overwhelming preference for double marking: not only are $92 \%$ of the verbs that mark the split twice transitive, as shown in Table 16a, but also $94.5 \%$ of all transitive verbs mark it twice, as shown in Table 16b. Similarly, intransitive verbs prefer a stem-based only split.

Table 16. Number split type according to transitivity.

\begin{tabular}{|c|c|c|c|c|c|c|}
\hline a. & \multicolumn{2}{|c|}{ TAM-based } & \multicolumn{2}{|c|}{ Stem-based } & \multicolumn{2}{|c|}{ Both } \\
\hline $\operatorname{tr}$ & 12 & $36.5 \%$ & 4 & $7 \%$ & 280 & $92 \%$ \\
\hline intr & 21 & $63.5 \%$ & 51 & $93 \%$ & 25 & $8 \%$ \\
\hline Total & 33 & $100 \%$ & 55 & $100 \%$ & 305 & $100 \%$ \\
\hline b. & $\operatorname{tr}$ & & int & & Bot & \\
\hline TAM-based only & 12 & $4.0 \%$ & 21 & $21.5 \%$ & 280 & $92 \%$ \\
\hline Stem-based only & 4 & $1.5 \%$ & 51 & $52.5 \%$ & 25 & $8 \%$ \\
\hline Both & 280 & $94.5 \%$ & 25 & $26 \%$ & 305 & $100 \%$ \\
\hline Total & 296 & $100 \%$ & 97 & $100 \%$ & & \\
\hline
\end{tabular}

But despite such correlations, as the split is not predictable one cannot overlook the fact that there is a breach in Amuzgo grammar affecting the mapping between what is required by the syntax (i.e. agreement in number of subject) and what is actually reflected by the morphology. This breach has consequences for the morpho-syntax, as it has to be filtered out through information stored in the lexicon. The total number of verbs in our sample undergoing some type of stem change is 360 . Of these, as we will see in $\S 5.5$, the only ones for which the form of the plural stem is predictable from the singular and vice versa are verbs bearing the stem formative pair $t s(i)^{5}+/ n \tilde{a} P^{1}+$. Such verbs amount to 190 in our 
sample. For the remaining 170 verbs, speakers need to remember two stems independently. ${ }^{13}$

In the following two sections, we introduce the way the number split is manifested in these two domains. But as the split at stem level is more intricate due to the existence of a great deal of allomorphy, we begin with the TAM-based split next.

\section{The TAM-based number split}

Based on FT's data, verbs in San Pedro Amuzgo can be classified as belonging to at least six different inflectional classes depending on how they mark the incompletive aspect. The phenomenon is illustrated by the seven verbs in Table 17. To appreciate the morphology involved in the encoding of the incompletive more clearly, we provide the forms for the completive for comparison. In the segmentation, composite elements in a verbal compound are indicated by an en-dash (-).

\section{SEE TABLE 17 ON THE FINAL PAGE}

As shown in Table 17, the classes are unequal in size. We focus on the first three. Here the distribution of the markers for the incompletive reveals a singular vs. plural split, where the persons of the plural all receive the same marker $\mathrm{ko}$-, while the persons of the singular receive different encodings. Class 1 verbs have a marker $m a^{3}$ - for both the 1 st and 2 nd persons singular and $2^{5}$ - for the 3rd person singular. This contrasts with Classes 2 and 3 which do not differentiate person in the singular; they have either ba- or zero marking. It is interesting that the plural marker $k o$ - of Classes $1-3$ is homophonous to the generalized incompletive marker for verbs of Class $4 .{ }^{14}$ The same happens for the $b a$ - and the zero marking of the singular of Classes 2 and 3, which are used as generalized incompletive markers for Classes 5 and 6, respectively.

The figures in Table 18 show how the verbs in the sample are distributed across the incompletive classes according to whether they display a TAM-based split or not and to whether they are inactive or active.

\footnotetext{
${ }^{13}$ Of course this only applies to the verbs of our sample. If more verbs were added, the number of verbs for which remembering two stems is required would obviously increase.

${ }^{14}$ One way to interpret this is to view inactive verbs as derived from Class 1 verbs. There is some evidence which points in this direction, although a proper study of this phenomenon needs to be left for future research. For example, $?^{5} \mathrm{Wa}^{1}$ 'cut' is a transitive verb of Class 1 (3SG.INCPL ${ }^{5}-[?] W a^{1}=h \tilde{o}^{53}$ vs. 3PL.INCPL $k o^{3}-t$ $\left.? w a^{3}=h o^{5}\right)$. Its middle counterpart 'cut oneself by accident' is instead a Class 4 inactive verb (3SG.INCPL $k o^{3}-$ $t-P w a^{1}=\tilde{e}^{3}$ vs. 3PL.INCPL $\left.k o^{3}-t-P w a^{1}=\tilde{e}^{3}\right)$. Notice that the middle verb, as a Class 4 verb, does not only use $k o^{3}$-in all the forms of the incompletive but also uses the plural stems for all forms.
} 
Table 18. The distribution of the TAM-based split across inactive/active verbs.

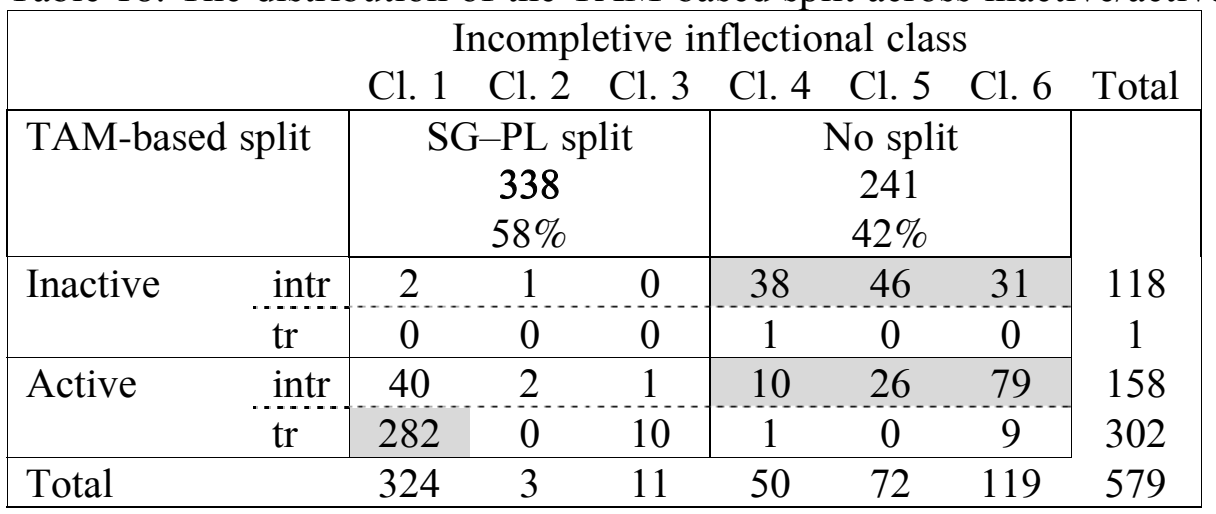

Table 18 reveals that $58 \%$ of the verbs in the sample display a TAM-based split involving the marking for the incompletive. Of these, only three are inactive. This means that if a verb is inactive it will most likely not have a TAM-based split either. Being active is, on the other hand, uninformative: out of the 460 active verbs, while 335 display a TAM-based split, there still remain 125 that do not. In contrast, we can see a strong correlation with transitivity: 282 out of the 302 transitive (active) verbs in the sample are members of Class 1 and thus display the TAM-based split. The profile of the Classes 4-6, not having the split, is more heterogeneous.

Table 19 gives an indication of how the incompletive classes correlate with the 360 verbs that have a stem-based split. The overall majority corresponds to Class 1 verbs (81\%), and since Class 1 verbs by definition have a TAM-based split, they end up showing the split at least twice in the relevant forms. If we sum up all verbs of Classes 4-6 in Table 19 we obtain 55 of them; most significantly, 51 of them (93\%) are intransitive.

Table 19. Correlation between the TAM-based split and the stem-based split.

\begin{tabular}{|lccc|c|c|}
\hline \multicolumn{2}{|l}{ Incompletive inflectional class } & \multicolumn{2}{c}{ Stem-based split } & intr & tr \\
\hline SG-PL split & Class 1 & 292 & $81 \%$ & 22 & 270 \\
& Class 2 & 2 & $0.7 \%$ & 2 & 0 \\
& Class 3 & 11 & $3 \%$ & 1 & 10 \\
\hline No split & Class 4 & 1 & $0.3 \%$ & 1 & 0 \\
& Class 5 & 11 & $3 \%$ & 11 & 0 \\
& Class 6 & 43 & $12 \%$ & 39 & 4 \\
\hline Total & & 360 & $100 \%$ & 76 & 284 \\
\hline
\end{tabular}

We end this section by noting that the incompletive as an aspectual value is not a category which is intuitively related to the agreement in number with the subject. Consequently, a TAM-based split as witnessed by the contrasts involved in Classes 1-3 could be seen as epiphenomenal to number agreement. As a result, showing that Amuzgo verbs also rely on stem changes to produce the number split is fundamental to our argumentation. In Table 19 we are reminded that 360 verbs in the sample display a stem-based split. In the following section we delve into the morphological intricacies of such stems.

\section{The split at the level of the stem}

Verbs in Amuzgo may also display a number split in the domain of the verbal stem. For this, verbs have two stems, one used to build the inflected forms when the subject is singular and another when the subject is plural. In our sample of 579 verbs, 360 (62\%) 
display the number split at the level of the stem in some way or another. Whether a given verbal lexeme will display the split or not is not predictable, and in principle, speakers need to know which lexemes do and which do not. But to make matters more interesting from a morphological point of view, for those that do, speakers also need to know how the two stems differ from one another.

In this respect, we have identified a set of formal ways or strategies by which the two stems may differ, namely: (a) by means of glottalization; (b) by replacing a final vowel; (c) by adding the prefix $t-;$ (d) by adding the prefix $n-;$ (e) by means of stem formatives; (f) by a combination of at least two of the aforementioned mechanisms, $(\mathrm{g})$ by having a suppletive stem; or (h) by a change in tone. In Table 20, we give an indication of the frequency of such operations in our sample together with an example.

Table 20. Operations involving the stem-based split.

\begin{tabular}{|c|c|c|c|c|c|c|}
\hline & Strategy & \# & $\%$ & SG & $\mathrm{PL}$ & \\
\hline a. & Glottalization & 18 & $5 \%$ & $h n a^{3} n o^{3}$ & hnaP' $^{l}$ no $^{l}$ & 'flee' \\
\hline b. & Final vowel & 11 & $3 \%$ & $n d y-i^{35}$ & $n d y-e^{1}$ & 'hear' \\
\hline c. & Prefix $t-$ & 69 & $19 \%$ & $k i^{5}$ & $t-k i^{5}$ & 'eat' \\
\hline d. & Prefix $n-$ & 12 & $3.5 \%$ & tykwã $?^{3}$ & $n$-tykwãa? ${ }^{3}$ & 'have a handicap' \\
\hline e. & Stem formatives & 190 & $53 \%$ & $t s i^{5}+$ ty?ue $e^{3}$ & nã? $P^{1}+$ ty?ue $e^{3}$ & 'scare' \\
\hline f. & Combination & 9 & $2.5 \%$ & $\operatorname{skuP}^{12}$ & $n-t-k u^{12}$ & 'have a wife' \\
\hline g. & Suppletion & 24 & $6.5 \%$ & tsku? $^{1}$ & $t \varepsilon P^{3}$ & 'close' \\
\hline h. & Tone only & 27 & $7.5 \%$ & ndui? ${ }^{1}$ & ndui? ${ }^{3}$ & 'go out' \\
\hline & Total & 360 & $100 \%$ & & & \\
\hline
\end{tabular}

The strategy involving stem formatives is the most frequent and is also the most transparent: knowing that a verb in the singular has a stem formative of a certain type would enable us to predict what stem formative the plural forms take. For the other cases, making predictions is a little less obvious. All operations are unproductive and we suggest that treating the stem contrasts as cases of suppletion is perhaps the best way to characterize the variance.

Another relevant factor that reinforces the relation between the singular and the plural stems as being one of suppletion, whether partial or total, is the intricate use of tone. In Table 20, we observe that there are 27 verbs whose stems contrast in tone only (we will further see in $\S 5.8$ that they fall into different tone classes). However, at least 106 of the remaining verbs, whose stems contrast by means of one of the different segmental encoding strategies in (a-g), also use tone as an additional encoding strategy. The details are given in Table 21.

Table 21. Distribution of tone in the marking of a stem-based split.

\begin{tabular}{|c|c|c|c|c|c|}
\hline \multirow{3}{*}{$\begin{array}{l}\text { Without tone change } \\
\text { With tone change }\end{array}$} & \multirow{3}{*}{$\begin{array}{l}225 \\
133\end{array}$} & \multirow{3}{*}{$\begin{array}{l}63 \% \\
37 \%\end{array}$} & & & \\
\hline & & & Tone only & & $20 \%$ \\
\hline & & & $\begin{array}{l}\text { Tone change in addition } \\
\text { to another segmental change }\end{array}$ & 106 & $80 \%$ \\
\hline Total & 360 & $100 \%$ & Total & 133 & $100 \%$ \\
\hline
\end{tabular}

Besides, as we have already pointed out in Table 15 above, 305 (85\%) out of the 360 verbs that have a stem-based split belong to one of the three classes that also reflect the number split in the incompletive. As a result, when a verb of these classes is inflected in the 
incompletive, the plural forms manifest the split twice, that is, in two domains: in both the affixal and the stem domains. This is shown in Table 22a with the verb ch?ue ${ }^{35}$ 'steal, pick' which has its plural stem marked with a nasal prefix (plus a predictable morphophonological adjustment to the root) and the incompletive prefix $\mathrm{ko}$ - Note that tone does not change; we find the same tone $/ 35$ / in the stem of both forms for the 3rd person. When the verb employs a combination of stem-based strategies, the inflected forms may display the split in various places. We illustrate this with the verb $n d y u i^{35}$ 'tread' in Table 22 , whose plural stem contrasts with the singular stem in both the final vowel and in tone. In more extreme cases, like the verb $b a^{3} n k h e ?^{35}$ 'pick up', we may find plural subject marked in four places in an inflected form: by (i) the presence of the prefix $t$-, (ii) the change in tone in the /ba/ segment in the first syllable of the stem; (iii) the glottalization at root level; and (iv) the incompletive prefix $\mathrm{ko}$.

Table 22. Verbs manifesting the singular-plural split by multiple means

\begin{tabular}{|c|c|c|c|}
\hline INCPL & $\begin{array}{c}\text { a. } \\
\text { 'steal, pick' }\end{array}$ & b. & $\begin{array}{c}\text { c. } \\
\text { 'pick up' }\end{array}$ \\
\hline $1 \mathrm{SG}$ & $m a^{3}-\operatorname{ch} P u\langle\varepsilon\rangle^{53}$ & $m a^{3}-$ ndyu-i ${ }^{53}$ & $m a^{3}-b a^{5}$ nkh $\langle\varepsilon\rangle ?^{53}<$ \\
\hline $2 \mathrm{SG}$ & $1^{3}-\operatorname{ch} 2 u e^{53}-?$ & $m a^{3}-$ ndyu-i ${ }^{53}-?$ & $m a^{3}-b^{5} n k h e^{31}-?$ \\
\hline $3 \mathrm{SG}$ & h?ue 35 & lyu-i $i^{35}$ & $2^{5}-$ \\
\hline 1PL.INCL & $\mathrm{ko}^{3}-\mathrm{n}-\mathrm{dy} \mathrm{u}$ & $\mathrm{ko}^{3}$-ndyu- $\langle\varepsilon\rangle^{12}$ & $\mathrm{ko}^{3}-\mathrm{t}-(\mathrm{b}) \mathrm{a}^{1} \mathrm{Pnkh}$ \\
\hline 1PL.EXCL & $\mathrm{ko}^{3}-\mathrm{n}$ & $\mathrm{ko}^{3}-\mathrm{ndyu}-\mathrm{e}^{51}$ & $k^{3}-t-(b) a^{1} P n k h e$ \\
\hline $2 \mathrm{PL}$ & $-d y ? u e^{35}=o ?^{3}$ & $\mathrm{ko}^{3}-\mathrm{ndyu}^{\mathrm{e}} \mathrm{e}^{1}=\mathrm{o} ?^{3}$ & $k o^{3}-t-(b) a^{1}$ ?nkhe \\
\hline 3PL & $\mathrm{ko}^{3}-\mathrm{n}-\mathrm{dy} ? \mathrm{ue} \mathrm{e}^{35}=\mathrm{ho}^{5}$ & $\mathrm{ko}^{3}-$ ndyu $^{-\mathrm{e}^{1}}=\mathrm{ho}^{5}$ & ko $^{3}$-t-(b)a $a^{1}$ nkhe ${ }^{35}=h^{5}$ \\
\hline
\end{tabular}

In order to understand the nature of the contrasts between the singular and the plural stems, we take here the singular as a point of departure. The rampant arbitrariness of the different possibilities makes it clear that the derivation does not obey any transparent or productive rule, at least synchronically. In the following sections, we will present each strategy in some detail.

\subsection{Stems contrasting in glottalization}

Some verbs in Amuzgo have two stems that contrast in glottalization: one of them is used for the singular and the other for the plural. Examples are given in Table 23. The distribution of the stems in these examples is according to the number of the subject. This is a different phenomenon from the glottalization classes mentioned in $\$ 2.2$, as proposed in Kim (to appear), where the two stems (glottalized and non-glottalized) are distributed according to more morphological (i.e. less meaningful) patterns, as seen for example with the verb biP' ${ }^{12}$ 'get sick' in Table 6.

Table 23. Two verbs with stems contrasting in glottalization

\begin{tabular}{|c|c|c|}
\hline CPL & 'flee' & 'get scared' \\
\hline $1 \mathrm{SG}$ & hna $^{3} n\langle 0\rangle^{53}$ & tyPu$\langle\varepsilon\rangle^{1}$ \\
\hline $2 \mathrm{SG}$ & hna $^{3}$ no- $?^{12}$ & ty?ue- $?^{3}$ \\
\hline $3 \mathrm{SG}$ & $\mathrm{hna}^{3} \mathrm{no}^{3}$ & ty?ue ${ }^{3}$ \\
\hline 1PL.INCL & hnaP $^{1} n\langle 0\rangle^{12}$ & tyu $\varepsilon^{34}$ \\
\hline 1PL.EXCL & $\mathrm{hna}^{1} \mathrm{no}^{51}$ & tyue $^{51}$ \\
\hline 2PL & hna? $^{1}$ no ${ }^{1}$ o? $^{3}$ & tyue $^{3}$ o $?^{3}$ \\
\hline $3 \mathrm{PL}$ & hnaP $^{1}$ no $^{1}\left(\right.$ ho $\left.^{5}\right)$ & tyue $^{3}\left(h^{5}\right)$ \\
\hline
\end{tabular}


In Table 23, the singular-plural split is manifested by a contrast in the glottalization of the stem. There are 18 verbs like this in FT's sample, given in Table 24. Of these, 15 others are like $h n a^{3} n o^{3}$ 'flee' in having the glottalized stem in the plural while having a concomitant tone change /3/ vs. /1/, i.e. $h n a{ }^{3} n o^{3}$ vs. $h n a P^{1} n o o^{115}$ In contrast, the two verbs listed under (b) in Table 24 have the glottalized stem in the singular. The last verb, nde? 'bathe', shows glottal metathesis rather than the addition of a new glottal.

Table 24. Verbs with stems contrasting in glottalization

\begin{tabular}{|c|c|c|c|}
\hline & SG & PL & \\
\hline \multirow[t]{15}{*}{ a. } & $\mathrm{hna}^{3} \mathrm{no}^{3}$ & hna? $^{1}$ no $^{1}$ & 'flee' \\
\hline & te $^{3}$ hndi $^{5}$ & te $^{1} \mathrm{Phndi}^{5}$ & 'support, help' \\
\hline & chui $^{3}$ no $^{53}$ & chui ${ }^{1} \mathrm{PnO}^{53}$ & 'get confused' \\
\hline & $\mathrm{be}^{3}+$ hndya $^{1}$ & $\mathrm{be}^{1}+$ ?hndya ${ }^{1}$ & 'cross' \\
\hline & $\mathrm{be}^{3}+\mathrm{t}^{2} \mathrm{io}^{1}$ & $\mathrm{be}^{1}+$ Pt?io $^{1}$ & 'cross' \\
\hline & $\mathrm{be}^{3}+$ ndo $^{34}$ & $\mathrm{be}^{1}+$ Pndo $^{34}$ & 'wait' \\
\hline & $\mathrm{ke}^{3}+\mathrm{na} \mathrm{P}^{35}$ & $\mathrm{ke}^{1}+$ ?nã ${ }^{35}$ & 'remove' \\
\hline & $\mathrm{ke}^{3}+\mathrm{ntho}^{12}$ & $\mathrm{ke}^{1}+$ ?ntho ${ }^{12}$ & 'run over' \\
\hline & ndyo $^{3}$-tska? ${ }^{5}$ & ndyo $^{1}-$ Ptska? ${ }^{5}$ & 'drag' \\
\hline & $n d o^{3} n d \varepsilon^{34}$ & $n d o^{1}-2 n d \varepsilon^{34}$ & 'look up' \\
\hline & tyi $i^{3}-x e ?^{34}$ & tyi ${ }^{1} P x e e^{34}$ & 'feed' \\
\hline & ndyo $^{3}$ ndyi $^{34}$ & ndyo $^{1}$ Pndyi $^{34}$ & 'lean out' \\
\hline & ndyo $^{3}$ ts?a $^{35}$ & ndyo ${ }^{1} \mathrm{Pts}^{3} \mathrm{a}^{35}$ & 'hug' \\
\hline & $n a^{3}+n^{3}$ & $\mathrm{na}^{1}+2 \mathrm{no}^{1}$ & 'run, flee' \\
\hline & $\begin{array}{l}n a^{3}+b a^{3}-\text { ndye }^{1} \\
n a^{3}+k^{3}-\text { ntyha }^{3}\end{array}$ & $\begin{array}{l}\text { na }^{1}+2 \mathrm{ba}^{1}-\text { ndye }^{1} \\
\text { na }^{1} 2+\mathrm{ki}^{1}-\text { ntyha }^{1}\end{array}$ & $\begin{array}{l}\text { 'jump on the spot' } \\
\text { 'get up' }\end{array}$ \\
\hline \multirow[t]{2}{*}{ b. } & ty?ue & tyue $^{3}$ & 'get scared' \\
\hline & nõ $?^{3}$ & no ${ }^{1}$ & 'nominate' \\
\hline c. & nd $\varepsilon ?^{35}$ & $n d ? \varepsilon^{12}$ & 'bathe' \\
\hline
\end{tabular}

\subsection{Stems contrasting in the final vowel}

At least 11 verbs in our sample have stems which contrast in the singular and plural with regard to their final vowel. Three representative examples are given in Table $25 .{ }^{16}$

Table 25. Three verbs with stems contrasting in the final vowel

\begin{tabular}{|c|c|c|c|}
\hline INCPL & 'hear' & 'handle' & 'get drunk' \\
\hline $1 \mathrm{SG}$ & $m a^{3}-n d y-i^{53}$ & $m^{3}-n d y ?-u^{53}$ & $\varnothing-k i^{5} n d y-\langle 0\rangle^{3}$ \\
\hline $2 \mathrm{SG}$ & $m a^{3}-n d y-i^{53}-?$ & $m a^{3}-n d y-u^{53}-?$ & $\varnothing-k i^{5} n d y-u^{3}-?$ \\
\hline $3 \mathrm{SG}$ & $2^{5}-n d y-i^{35}$ & $2^{5}$-ndy-u $2^{35}$ & $\varnothing-k i^{5} n d y-i^{5}$ \\
\hline 1PL.INCL & $\mathrm{ko}^{3}-\mathrm{ndy}-\langle\varepsilon\rangle^{12}$ & $\mathrm{ko}^{3}$-ndy?-〈o $\rangle^{12}$ & $\varnothing-k i^{5} \mathrm{ndy}\langle\varepsilon\rangle^{5}\langle\varepsilon\rangle^{5}$ \\
\hline 1PL.EXCL & $k^{3}-n d y-e^{51}$ & ko $^{3}-n d y ?-o^{51}$ & $\varnothing-k i^{5} n d y-e^{51}$ \\
\hline $2 \mathrm{PL}$ & $\mathrm{ko}^{3}-\mathrm{ndy}^{-\mathrm{e}^{1}}$ o $?^{3}$ & $\mathrm{ko}^{3}$-ndy?-o ${ }^{12} \mathrm{o}^{3}$ & $\varnothing-k i^{5} n d y-e^{5}$ o $?^{3}$ \\
\hline $3 \mathrm{PL}$ & ko $^{3}-$ ndy-e $^{1}\left(\mathrm{ho}^{5}\right)$ & $\mathrm{ko}^{3}$-ndy?-o ${ }^{12}\left(\mathrm{ho}^{5}\right)$ & $\varnothing-k i^{5} n d y-e^{5}\left(h o^{5}\right)$ \\
\hline
\end{tabular}

\footnotetext{
${ }^{15}$ We have taken seven verbs from S\&S's sample that display both glottalization and the tone change /3/ vs. $/ 1 /$ as instances of this type of contrast despite the fact that we don't have evidence from their entire paradigm to discard the possibility that they are members of a glottalization class (as described by Kim, to appear).

${ }^{16}$ The verbs in Table 25 receive different marking for the incompletive because they belong to different classes, $P^{5} n d y i^{35}$ 'hear' and $P^{5} n d y u P^{35}$ 'handle' are from Class 1 , while $k i^{5} n d y i^{5}$ 'get drunk' is from Class 6 (see Table 17 for more details).
} 
The verbs 'hear' and 'feel your way' have two stems: $n d y i^{35}$ and $n d y ? u^{53}$ in the singular, respectively, and $n d y e^{1}$ and $n d y ? o^{12}$ in the plural. The two stems also contrast in tone, but we will return to this phenomenon in $\S 5.8$. The verb 'get drunk' is similar to these two verbs (i.e. it has $k i^{5} n d y i^{5}$ in the singular and $k i^{5} n d y e^{5}$ in the plural), but it has two further stems for the 1 st and the 2 nd persons singular: $k i^{5} n d y o^{3}$ and $k i^{5} n d y u^{3}$, respectively. Related person splits are also attested elsewhere; we will review them in $\S 5.9$. The 11 verbs in our sample like the ones in Table 25 are given in Table 26.

Table 26. Verbs with stems contrasting in the final vowel

\begin{tabular}{|c|c|c|}
\hline SG & PL & \\
\hline$n d y-i^{35}$ & ndy-e ${ }^{1}$ & 'hear' \\
\hline tu-i $\mathrm{i}^{35}$ & tu- $\mathrm{e}^{1}$ & 'put in' \\
\hline ndyu-i $i^{35}$ & ndyu-e $^{1}$ & 'kick', 'tread' \\
\hline$t ? u-i^{35}$ & t?u-e ${ }^{1}$ & 'grab', 'touch' \\
\hline Pndy-i ${ }^{35}$ & Pndy-e ${ }^{1}$ & 'leave' \\
\hline $\mathrm{ki}^{5} \mathrm{ndy- \textrm {i } ^ { 5 }}$ & $\mathrm{ki}^{5} \mathrm{ndy}-\mathrm{e}^{5}$ & 'get drunk' \\
\hline$n d i^{5}+$ Phnd-i ${ }^{5}$ & $n d i^{5}+$ ?hnd- $\varepsilon^{3}$ & 'be fat', 'be strong' \\
\hline $2^{5} \mathrm{hnd}-\mathrm{i}$ & $2^{3} \mathrm{hnd}-\varepsilon^{5}$ & 'have strength', 'be fat' \\
\hline ndyo ${ }^{1} \mathrm{ch}-\mathrm{u}^{5}$ & ndyo $^{3} \mathrm{ch}-\mathrm{o}^{1}$ & 'bring' \\
\hline ndy-u? $\mathrm{P}^{35}$ & ndy?-o $^{12}$ & 'handle', 'tempt' \\
\hline tyion $^{3}$ na $^{3}$ ch- $\mathrm{u}^{5} \mathrm{hna}^{51}$ & tyion $^{3}$ na $^{3}$ ch-o $^{5}$ hna $^{51}$ & 'pay a debt' \\
\hline
\end{tabular}

\subsection{Plural stems taking the prefix $t$ -}

There are 69 verbs in our sample whose plural stems bear a prefix, $t$-. The mechanism is typically associated with transitive verbs: 56 of the 69 verbs are transitive. Examples of verbs bearing this prefix are presented in Table 27.

Table 27. Verbs with the prefix $t$-.

\begin{tabular}{|c|c|c|c|c|c|}
\hline SG & PL & & & & \\
\hline $\mathrm{ki}^{5}$ & $\left\{\mathrm{t}-\mathrm{ki}^{5}\right\}$ & $/ \mathrm{t}-\mathrm{X} /$ & $\rightarrow$ & $\mathrm{tki}^{5}$ & 'eat' \\
\hline $\mathrm{bPa}^{3}$ & $\left\{t-b P a^{12}\right\}$ & $/ \mathrm{t}-\mathrm{bX} \rightarrow \mathrm{t}-\mathrm{X} /$ & $\rightarrow$ & $\mathrm{t}^{12}$ & 'grab', 'collect' \\
\hline $\mathrm{ma}^{1}$ & $\left\{t-m a^{3}\right\}$ & $\mathrm{t}-\mathrm{o} \mathrm{V} /$ & $\rightarrow$ & to $\tilde{a}^{3}$ & 'wash' \\
\hline me ${ }^{1}$ nda? & $\left\{t-m e e^{3}\right\}$ nda? & $\mathrm{t}-\mathrm{mV} \rightarrow \mathrm{t}-\mathrm{OV} /$ & $\rightarrow$ & toẽ ${ }^{3}$ nda? & 'hit with one's hand' \\
\hline kha? $^{35}$ & $\left\{\mathrm{t}-\mathrm{kha2^{35 }}\right\}$ & $/ \mathrm{t}-\mathrm{kX} \rightarrow \mathrm{t}-\mathrm{X} /$ & $\rightarrow$ & tha? $2^{35}$ & 'sting' \\
\hline kwha? $P^{35}$ & $\left\{\right.$ t-kwha $\left.{ }^{35} P\right\}$ & $/ \mathrm{t}-\mathrm{kwX} \rightarrow \mathrm{t}-\mathrm{X} /$ & $\rightarrow$ & thaa ${ }^{35}$ ? & 'repair' \\
\hline $\mathrm{ndo}^{3} \mathrm{Pbi}^{1}$ & $\left\{t-n d o^{12} P b i i^{1}\right\}$ & $/ \mathrm{t}-\mathrm{NX} \rightarrow \mathrm{NX} /$ & $\rightarrow$ & hndo $^{12} \mathrm{bi}^{1}$ & 'curse (witchcraft)' \\
\hline tha $a^{53}$ & $\left\{\mathrm{ti}^{3}-\mathrm{tha}^{53}\right\}$ & $/ \mathrm{ti}^{3}-\mathrm{X} /$ & $\rightarrow$ & $\mathrm{ti}^{3}$ tha $^{53}$ & 'be missing' \\
\hline
\end{tabular}

Most verbs bearing an alveolar prefix in the plural stem have some form of the prefix $t$-, but in FT's sample there are two verbs which have a syllabic prefix $t i^{3}-$, like tha ${ }^{53}$ 'be missing'. Affixing $t$-produces a series of regular morphophonological adjustments to the onset of the stem, which are also indicated in Table 27. Such adjustments are similar to the ones observed in the forms for the completive, an aspect that is also marked by a homophonous prefix $t$ - There, the completive prefix is dropped before stems with an onset in $/ \mathrm{t} /:$ e.g. 3SG.INCPL $P^{5}$-tiu ' ${ }^{1}$ whistle' but 3SG.CPL $t$-tiu ${ }^{1} \rightarrow$ tiu ${ }^{1}$. Taking this into consideration, we have assumed that at least nine verbs which have an onset in $/ \mathrm{t} /$ in our sample are also examples of plural stems with $t$-. But to be on the safe side, we have only considered those that also display a tonal change. We have proceeded in this way based on the observation that of the other 60 verbs, no less than 48 also involve a tonal change (80\%). An example of such a 
verb would be 'whistle': SG $t i u^{1}$ vs. PL $t$-tiu ${ }^{3} \rightarrow t i u^{3}$. As we will see in $\S 5.8$, tonal changes are independent of the prefix $t$-, but their co-occurrence with this prefix is particularly common to justify taking these nine verbs as instances of the prefix $t$ -

\subsection{Plural stems taking the prefix $n-$}

Twelve verbs in our sample have a plural stem marked with a nasal prefix. Examples are given in Table 28. Notice the different stem adjustments in the plural, which are due to regular morphophonological rules.

Table 28. Verbs with the prefix $n$-.

\begin{tabular}{|c|c|c|c|}
\hline SG & PL & & \\
\hline tykwã? ${ }^{3}$ & $n t^{\mathrm{j}} \mathrm{CV} \rightarrow$ & n-tykwã $2^{3}$ & 'have a handicap', 'be one-armed' \\
\hline$n d i^{5}+$ tsa? $^{3}$ & ntsV $\rightarrow$ n_V & $n d i^{5}+n-a ?^{3}$ & 'go crazy' \\
\hline$n d i^{5}+t^{2} ? \tilde{o}^{3}$ & $\mathrm{nts} ? \mathrm{~V} \rightarrow \mathrm{n}$ & $n d i^{5}+n-? o^{3}$ & 'go stiff' \\
\hline tshwẽ $\}^{3}$ & $n t s \mathrm{~h} \rightarrow \mathrm{n}$ & n-hwẽ ${ }^{1}$ & 'own an animal' \\
\hline$x \tilde{e} 1^{12}$ & $\mathrm{n} \int \mathrm{V} \rightarrow \mathrm{nkV}$ & $n-k \tilde{e}^{12}$ & 'have a father- or brother-in-law' \\
\hline xhẽ ${ }^{5}$ & $\mathrm{n} \int^{\mathrm{h}} \mathrm{V} \rightarrow \mathrm{nk}^{\mathrm{h}} \mathrm{V}$ & $n-k h \tilde{e}^{5}$ & 'have recently given birth' \\
\hline $\begin{array}{l}x ? \tilde{e}^{5} \\
n d i^{5}+k i^{5}-x ? \tilde{e}^{5}\end{array}$ & $\mathrm{n} \int \mathrm{PV} \rightarrow \mathrm{nk} ? \mathrm{~V}$ & $\begin{array}{l}n-k ? \tilde{e}^{5} \\
n d i^{5}+n-k ? \tilde{e}^{5}\end{array}$ & $\begin{array}{l}\text { 'bother' } \\
\text { 'bother' }\end{array}$ \\
\hline $\begin{array}{l}\text { ne }^{1}+\text { ki }^{3}-\text { chiu }^{35} \\
\text { chiu }^{35} \\
\text { chPue }^{35} \\
\text { ndi }^{5}+\text { chio }^{35}\end{array}$ & $n t \int V \rightarrow$ nd $^{j} V$ & $\begin{array}{l}\tilde{\text { ne }}{ }^{1}+\text { ki }^{3}-n-d y P i u^{12} \\
\text { n-dyPiu } \\
\text { n-dy?ue } \\
\text { ndi }^{5}+\text { n-dyio } \\
35\end{array}$ & $\begin{array}{l}\text { 'feel like urinating' } \\
\text { 'urinate' } \\
\text { 'rob' } \\
\text { 'go pale' }\end{array}$ \\
\hline
\end{tabular}

The nasal prefix is the plural marker for nouns and similar regular morphophonological adjustments are found in nouns, see Buck (2000: 394ff). This is illustrated in Table 29.

Table 29. Plural nouns with the prefix $n$-.

\begin{tabular}{|c|c|c|c|}
\hline SG & PL & & \\
\hline $\operatorname{tye}^{34}$ & $n \mathrm{t}^{\mathrm{j}} \rightarrow$ & n-tye ${ }^{34}$ & 'priest' \\
\hline tsõ $2^{51}$ & $\mathrm{nts} \tilde{\mathrm{V}} \rightarrow \mathrm{n} \_\mathrm{V}^{17}$ & $n-o ?^{51}$ & 'drum' \\
\hline tshã $2^{3}$ & $n t s^{\mathrm{h}} \mathrm{V} \rightarrow \mathrm{n} \_\mathrm{hV}$ & n-hã ${ }^{3}$ & 'sweet potato' \\
\hline$x \tilde{\mathrm{e}} ?^{1}$ & $\mathrm{n} \int \mathrm{V} \rightarrow \mathrm{nkV}$ & $n-k \tilde{e} e^{1}$ & 'back' \\
\hline $\mathrm{xho}^{1}$ & $\mathrm{n} \int^{\mathrm{h}} \mathrm{V} \rightarrow \mathrm{nk}^{\mathrm{h}} \mathrm{V}$ & n-kho ${ }^{1}$ & 'metal' \\
\hline X?õ 53 & $\mathrm{n} \int \mathrm{PV} \rightarrow \mathrm{nk} ? \mathrm{~V}$ & $\mathrm{n}-\mathrm{k} 2 \tilde{\mathrm{o}}^{53}$ & 'boil' \\
\hline $\mathrm{chu}^{3}$ & nt $\int \mathrm{V} \rightarrow \mathrm{nd}^{\mathrm{j}} \mathrm{V}$ & $n-d y u^{3}$ & 'year' \\
\hline
\end{tabular}

While the verbs which receive a nasal prefix in the plural stem remain largely arbitrary, it is noteworthy that out of the 16 inactive verbs in our sample that have the number split, 8 of them select this prefix. Given the link to nominal number, the occurrence of the prefix $n$ - in these verbs may point to an old denominal origin of these inactive verbs.

\subsection{Stems contrasting in stem formatives}

Many verbs in Amuzgo manifest the singular-plural split by means of a stem contrast that involves stem formatives. There are two main types. The first type is shown in Table 30, with the verb $t s i^{5} h n d a^{l}$ 'buy', adapted from Buck (2000:441). Stem formatives are segmented from the root and indicated by the plus sign.

\footnotetext{
${ }^{17}$ For these cases, the vowel of the plural stem loses its nasal component.
} 
Table 30. A verb with the stem formatives $t s i^{5}+\sim n \tilde{a}^{1}+$

\begin{tabular}{|c|c|c|}
\hline INCPL & 'buy' & Stems \\
\hline $1 \mathrm{SG}$ & $\mathrm{ma}^{3}-\mathrm{tsi}{ }^{5}+\mathrm{hnda}^{12}$ & \multirow{3}{*}{$\mathrm{tsi}^{5}+\mathrm{hnda}^{1}$} \\
\hline $2 \mathrm{SG}$ & $m a^{3}-t_{s i}{ }^{5}+h_{n d a}{ }^{1}-?$ & \\
\hline $3 \mathrm{SG}$ & $2^{5}-\mathrm{tsi}^{5}+\mathrm{hnda}^{1}$ & \\
\hline 1PL.INCL & $\mathrm{ko}^{3}-\mathrm{na} \mathrm{P}^{1}+\mathrm{hnda}^{12}$ & \multirow{4}{*}{ nã ${ }^{1}+$ hnda $^{1}$} \\
\hline 1PL.EXCL & $\mathrm{ko}^{3}-\mathrm{na} \mathrm{P}^{1}+\mathrm{hnda}^{51}$ & \\
\hline $2 \mathrm{PL}$ & ko ${ }^{3}-n a ̃ ?^{1}+$ hnda $^{1} o ?^{3}$ & \\
\hline 3PL & $\mathrm{ko}^{3}-\mathrm{nã} \mathrm{P}^{1}+\mathrm{hnda}^{1}\left(\mathrm{ho}^{5}\right)$ & \\
\hline
\end{tabular}

The verb $t s i^{5} h n d a^{l}$ 'buy' has two stems: one used with singular subjects $\left(t s i^{5}+h n d a^{1}\right)$ and another with plural subjects $\left(n \tilde{a} P^{1}+h n d a^{1}\right)$. The singular stem bears the formative $t s i^{5}+$ and the plural $n \tilde{a} P^{1}+$. This formative pair served as the morphological means to produce causative verbs in Amuzgo. It is no longer productive, but the mechanism has left behind a large number of transitive verbs in the lexicon (185 in our corpus) together with a few active intransitives with agentive semantics ( 3 in our sample). For the singular, the formative $t s i^{5}+$ is reduced to $t s+$ before a stem with a vocalic onset or beginning with $/ \mathrm{k} /$, and sometimes before /b/. Examples are given in Table 31.

Table 31. Examples of causative verbs.

\begin{tabular}{|c|c|c|}
\hline SG & PL & \\
\hline tsi $^{5}+$ ty?ue $^{3}$ & nã $2^{1}+$ ty?ue $^{3}$ & 'scare' \\
\hline $\mathrm{tsi}^{5}+\mathrm{k}^{2} \mathrm{ua}^{35}$ & nã ${ }^{1}+\mathrm{k}^{2} \mathrm{ua} \mathrm{a}^{35}$ & 'make noise' \\
\hline $\operatorname{tsi}^{5}+$ nchur $^{51}$ & nã ${ }^{1}+$ nchuP $^{51}$ & 'fix' \\
\hline $\mathrm{tsi}^{5}+\mathrm{ts} \tilde{a} \mathrm{P}^{3}$ & nã $2^{1}+$ tsã ${ }^{3}$ & 'drive crazy' \\
\hline $\mathrm{tsi}^{5}+\mathrm{ba}^{3} / \mathrm{ts}+\mathrm{ba}^{53}$ & $n a{ }^{1}{ }^{1}+b a^{3}$ & 'lift' \\
\hline ts $+i a^{51}$ & nã ${ }^{1}+y^{1}$ & 'make' \\
\hline ts $+k \tilde{a}^{5}$ & $n \tilde{a} ?^{1}+k \tilde{a}^{5}$ & 'dry' \\
\hline $\mathrm{ts}+\mathrm{ke}^{34}$ & nã ${ }^{1}+k e 2^{34}$ & 'hurt, wound' \\
\hline ts $+\mathrm{kwa}^{3}-\mathrm{nd} \varepsilon \mathrm{r}^{51}$ & $n \tilde{a} \mathrm{P}^{1}+\mathrm{kwa}^{3}-\mathrm{nd} \varepsilon \mathrm{P}^{51}$ & 'turn around' \\
\hline
\end{tabular}

Causative verbs in Amuzgo are fossilized structures, but they originated from a light verb construction consisting of a series of two verbs. The morphs $t s i^{5}+$ and $n \tilde{a} P^{1}+$ are the reflexes of the two stems of the verb tsia ${ }^{51} / n a{ }^{1}{ }^{1} \mathrm{ya}^{1}$ 'make' used as a causative light verb. Besides, about 46 of the verbs of the $t s i^{5}+\sim n a ?^{1}+$ type in S\&S's sample still bear the morph $k i^{3}$, which is doubtless the relic of the inflectional prefix $k i^{3}$-, which is used for the subjunctive. ${ }^{18}$ We mark this by an underscore.

Table 32. Examples of causative verbs with the old prefix $k i^{3}-$

\begin{tabular}{|c|c|c|c|c|c|}
\hline SG & $\mathrm{PL}$ & & & Source ir & b \\
\hline $\mathrm{ki}^{3}{ }_{-} \mathrm{nd} \varepsilon^{35}$ & $n \tilde{a} 2^{1}+\mathrm{ki}^{3}{ }_{-} \mathrm{nd} \varepsilon^{35}$ & 'ripen' & $\sim$ & $\mathrm{nd} \varepsilon^{35}$ & 'be ri \\
\hline $\mathrm{tsi}^{5}+\mathrm{ki}^{3}{ }_{-} \mathrm{ndya}^{3}$ & nã ${ }^{1}+\mathrm{ki}^{3}{ }_{-}$ndya $^{3}$ & 'make spicy' & $\sim$ & ndya ${ }^{3}$ & 'be \\
\hline $\mathrm{tsi}^{5}+\mathrm{ki}^{3}{ }_{-} \mathrm{no}^{3}$ & $n \tilde{a} P^{1}+\mathrm{ki}^{3}{ }_{-}$no $^{3}$ & 'make run' & $\sim$ & nã $\tilde{a}^{3}-n \tilde{o}^{3}$ & 'run off' (Lit. 'exit-run') \\
\hline
\end{tabular}

\footnotetext{
${ }^{18}$ The use of this prefix is shown in Table 33. It has allomorphy, e.g. notice the allomorph $k w$ - in Table 5 above. In the complementation constructions of Oto-Manguean languages, which generally lack non-finite forms such as infinitives, it is very common to find the dependent clause marked with a special subordinating mood such as subjunctive, potential or irrealis.
} 
Apart from causative verbs, there is also a group of verbs in Amuzgo that are lexicalized forms of old $\mathrm{V}_{1} \mathrm{~V}_{2}$ compounds with the verb 'go' as $\mathrm{V}_{1}$. In the Surrey Morphology Group's database, there are 63 such verbs ( 42 from FT's dataset and 21 from S\&S) but we have only included four of them in our sample (one from FT's data and three transitive verbs from S\&S). The great majority of such verbs are intransitive, and most of them are motion or posture verbs, but at times it is difficult to identify semantic compositionality. The verbs in question could be characterized as bipartite, that is, as consisting of two components. To illustrate this, consider the verb $b a^{5}+k w a^{3}$ 'lie down' in Table 33.

Table 33. Three TAMs of the verb $b a^{5}+k w a^{3}$ 'lie down'

\begin{tabular}{|c|c|c|c|}
\hline & INCPL & CPL & SUBJV \\
\hline $1 \mathrm{SG}$ & $\varnothing-\mathrm{baP}^{1}+\mathrm{kwa}^{3}$ & ty- $\varepsilon ?^{1}+\mathrm{kwa}^{3}$ & $\mathrm{k}-\mathrm{or}^{1}+\mathrm{kwa}^{3}$ \\
\hline $2 \mathrm{SG}$ & $\varnothing-b^{3}+k w a^{3}-?$ & $\mathrm{t}-(\mathrm{b}) \mathrm{a}^{3}+k w \mathrm{a}^{3}-?$ & $\mathrm{k}-(\mathrm{b}) \mathrm{a}^{3}+\mathrm{kwa}^{3}-?$ \\
\hline $3 \mathrm{SG}$ & $\varnothing-\mathrm{ba}^{5}+\mathrm{kwa}^{3}$ & $\mathrm{t}-(\mathrm{b}) \mathrm{a} ?^{1}+\mathrm{kwa}^{3}$ & $\mathrm{k}-(\mathrm{b}) \mathrm{a}^{5}+\mathrm{kwa}^{3}$ \\
\hline 1PL.INCL & $\mathrm{ko}^{3}-\mathrm{tsa}^{5}+\mathrm{ki}^{3} \mathrm{mPa}^{34}$ & $\langle\mathrm{~s}\rangle \mathrm{a}^{5}+\mathrm{ki}^{3}{ }_{-} \mathrm{mPa}^{34}$ & $\mathrm{ki}^{3}-\mathrm{tsa}^{5}+\mathrm{ki}^{3} \mathrm{mPa}^{34}$ \\
\hline 1PL.EXCL & $\mathrm{ko}^{3}-\mathrm{tsa}^{5}+\mathrm{ki}^{3} \mathrm{mPa}^{51}$ & $\langle\mathrm{~s}\rangle \mathrm{a}^{5}+\mathrm{ki}^{3}{ }_{-} \mathrm{m} \mathrm{a}^{51}$ & $\mathrm{ki}^{3}-\mathrm{tsa}^{5}+\mathrm{ki}^{3} \mathrm{~m}_{-} \mathrm{a}^{51}$ \\
\hline $2 \mathrm{PL}$ & $\mathrm{ko}^{3}-\mathrm{tsa}^{5}+\mathrm{ki}^{3}-\mathrm{ma}^{1} \mathrm{ol}^{3}$ & $\langle\mathrm{~s}\rangle \mathrm{a}^{5}+\mathrm{ki}^{3} \mathrm{ma}^{-} \mathrm{m}^{1} \mathrm{o}^{3}$ & $\mathrm{ki}^{3}-\mathrm{tsa}^{5}+\mathrm{ki}^{3}-\mathrm{ma}^{1} \mathrm{oP}^{3}$ \\
\hline 3PL & $\mathrm{ko}^{3}-\mathrm{tsa}^{5}+\mathrm{ki}^{3} \mathrm{ma}^{1}\left(\mathrm{ho}^{5}\right)$ & $\langle\mathrm{s}\rangle \mathrm{a}^{5}+\mathrm{ki}^{3} \mathrm{ma}_{-}{ }^{1}\left(\mathrm{ho}^{5}\right)$ & $\mathrm{ki}^{3}-\mathrm{tsa}^{5}+\mathrm{ki}^{3} \mathrm{ma}^{1}\left(\mathrm{ho}^{5}\right)$ \\
\hline
\end{tabular}

The second component in such formations is the lexical element. In the example in Table 33 , this lexical element already has a singular-plural split at the stem level: we have $\mathrm{kwa}^{3}$ for the singular, and $k i_{-}^{3} m a P^{1}$ for the plural. ${ }^{19}$ The first component of the verb, meanwhile, has forms that are remnants of inflected forms of the verb $b h a^{5}$ ' $g o$ '. To see this, compare the inflection of the first component of the verb $b a^{5}+k w a^{3}$ 'lie down' in Table 33 with the forms of the verb $b h a^{5}$ 'go' in Table 34 from equivalent sub-paradigms.

Table 34. Three TAMs of the verb $b h a^{5}$ 'go'

\begin{tabular}{|c|c|c|c|}
\hline & INCPL & CPL & SUBJV \\
\hline $1 \mathrm{SG}$ & $\varnothing-h\langle 0\rangle^{1}$ & ty- $\langle\varepsilon\rangle^{1}$ & $\mathrm{k}-\mathrm{h}\langle\mathrm{o}\rangle^{1}$ \\
\hline $2 \mathrm{SG}$ & Ø-b_ha ${ }^{53}-?$ & $\mathrm{t}-\left(\mathrm{b}_{-}\right) \mathrm{ha}^{53}-\mathrm{P}$ & $\mathrm{k}-\left(\mathrm{b}_{-}\right) \mathrm{ha}^{53}-?$ \\
\hline $3 \mathrm{SG}$ & Ø-b_ha ${ }^{5}$ & $\mathrm{t}-\left(\mathrm{b}_{-}\right) \mathrm{ha}^{5}$ & $\mathrm{k}-\left(\mathrm{b}_{-}\right) \mathrm{ha}^{5}$ \\
\hline 1PL.INCL & $k o^{3}-2\langle 0\rangle^{5}$ & ty $-2\langle\varepsilon\rangle^{5}$ & $k-2\langle 0\rangle^{5}$ \\
\hline 1PL.EXCL & $\mathrm{ko}^{3}-\mathrm{tsa}^{51}$ & $\langle\mathrm{~s}\rangle \mathrm{a}^{51}$ & $\mathrm{ki}^{3}-\mathrm{tsa}^{51}$ \\
\hline $2 \mathrm{PL}$ & $\mathrm{ko}^{3}-1 \mathrm{o}^{5}=\mathrm{o} \mathrm{P}^{3}$ & ty- $-2 e^{5}=o 1^{3}$ & $\mathrm{k}-1 \mathrm{o}^{5}=\mathrm{o} \mathrm{P}^{3}$ \\
\hline $3 \mathrm{PL}$ & $\mathrm{ko}^{3}-1 \mathrm{o}^{5}\left(=\mathrm{ho}^{5}\right)$ & ty- $-\mathrm{e}^{5}\left(=\mathrm{ho}^{5}\right)$ & $\mathrm{k}-\mathrm{Po}^{5}\left(=\mathrm{ho}^{5}\right)$ \\
\hline
\end{tabular}

The first component of the plural stem of the verb in Table 33 has $t s a^{5}+$, which we take to function synchronically as a stem formative. This morph originated from the plural stem of the verb 'go' that we still observe today in the form for the 1st person plural exclusive. For the singular, the forms remind us of equivalent inflected forms of the verb 'go'; they bear an almost identical suppletion. But there are slight differences that justify their treatment as independent forms. Such formal differences together with the overall lack of semantic compositionality justifies treating verbs of this type as verbs that have idiosyncratic inflectional properties rather than just verbal compounds based on 'go'. All such verbs

\footnotetext{
${ }^{19}$ For more about this stem see note 21. In turn, the plural stem $k i_{-}^{3} \mathrm{ma}^{1}$ is the lexicalization of an inflected form bearing the subjunctive prefix $\mathrm{ki}^{3}$ - plus the genuine old plural stem ma? ${ }^{1}$. A similar structure is found in many causative verbs, as pointed out in Table 32, but at least for this verb and others like it (e.g.

$b a^{5}+k a n^{1} / t s a^{5}+k i_{-}^{3} t-(k) a n^{3}$ 'beg') the subjunctive structure is only circumscribed to the plural, which can be taken as a further indication of the great depth of the split.
} 
manifest the singular-plural split. This is achieved for all of them by means of the formal contrasts involving the first component, but for some of the verbs, for example the one in Table 33, the second component may also manifest the split independently. For such cases, we have double marking. This brings us to the next section where we show more instances of double marking at stem-level.

\subsection{The plural stem combines different marking strategies}

There are also verbs whose stems combine two of the strategies we have presented so far. The verbs that are found in our sample that behave in this way are given in Table 35.

Table 35. Verbs with exuberant plural marking

\begin{tabular}{|c|c|c|c|}
\hline SG & PL & & \\
\hline $\mathrm{ndi}^{5}+\mathrm{tsh}^{34}$ & $n-+t-$ & $\mathrm{ndi}^{5}+\mathrm{n}-\mathrm{t}-\mathrm{h} \mathrm{s}^{34}$ & 'be slow', 'be docile' \\
\hline $\mathrm{ts}^{3} \mathrm{a}^{35}$ & $n-+t-$ & $n-t-3 a^{1}$ & 'do' \\
\hline skuP $^{12}$ & $n-+\mathrm{t}-$ & $\mathrm{n}-\mathrm{t}-\mathrm{ku} \mathrm{u}^{12}$ & 'have a wife' \\
\hline$n d i^{5}+s k u^{1}$ & $n-+\mathrm{t}-$ & $n d i^{5}+n-t-k u^{1}$ & 'be beautiful' \\
\hline$n d i^{5}+\mathrm{ki}^{5}$ & $\mathrm{n}-+-\mathrm{e}$ & $n d i^{5}+n-k-e^{5}$ & 'harden' \\
\hline ba $^{3}$ nkhe? ${ }^{35}$ & $\mathrm{t}-+?-$ & $\mathrm{t}-(\mathrm{b}) \mathrm{a}^{1}$ Pnkhe ${ }^{35}$ & 'pick up, choose' \\
\hline $\mathrm{tsi}^{5}+\mathrm{ki}^{5}+\mathrm{ts} P \tilde{\mathrm{o}}^{3}$ & nã $P^{1}+n-$ & $n \tilde{a} P^{1}+k i^{5}+n-1 o^{3}$ & 'bear pain' \\
\hline $\mathrm{tsi}^{5}+\mathrm{ki}^{5}{ }_{-} \mathrm{ndy}-\mathrm{i}^{5}$ & nã $P^{1}+-e$ & $n a \tilde{2} P^{1}+\mathrm{ki}^{5}{ }_{-} \mathrm{ndy}-\mathrm{e}^{5}$ & 'make drunk' \\
\hline $\mathrm{ba}^{5}+\mathrm{kwa}^{3}-\mathrm{ngio}^{3}$ & $\mathrm{tsa}^{5}+$ Suppletion & $\mathrm{tsa}^{5}+\mathrm{ki}^{3}{ }_{-} \mathrm{maP}^{1}-\mathrm{ngio}^{3}$ & 'lie face down' \\
\hline
\end{tabular}

The existence of verbs like the ones in Table 35 can be taken as further evidence that the operations behind the building of plural stems have ceased to be productive, and are only connected to the lexicon as instances of partial suppletion. The last verb is an example of how the stem formative strategy can combine with root suppletion. This leads us to the next section where we present instances of suppletive stems which are more canonical.

\subsection{Suppletive stems}

Verbs with more canonical suppletive stems also occur in SP Amuzgo. The difference between the singular and plural stems can be one of total suppletion, like in Table 36a where the stems lack any element in common suggesting they probably come from different lexical sources. We also have cases of partial suppletion shown in Table 36b, where the plural stem is related to the singular stem, but only in obscure ways. 
Table 36. Verbs with suppletive stems.

\begin{tabular}{|c|c|c|c|}
\hline & SG & PL & \\
\hline \multirow[t]{9}{*}{ a. } & $\mathrm{ki}^{3}-\mathrm{ndyi}^{34}$ & $\mathrm{ki}^{5}$-to ${ }^{5}$ & 'be included' \\
\hline & $\tilde{\mathrm{n}} \mathrm{e}^{1}+\mathrm{ki}^{5} \mathrm{tso}^{5}$ & $\tilde{\mathrm{ne}} \mathrm{P}^{1}+\mathrm{ki}^{3}{ }_{-} \mathrm{nda}^{1}$ & 'be tired' \\
\hline & tsku? $^{1}$ & $\operatorname{t\varepsilon } ?^{3}$ & 'close', 'prohibit' \\
\hline & $\mathrm{t}^{\mathrm{eg}} \mathrm{o}^{35}$ & tyue $^{35}$ & 'cry' \\
\hline & ncchi $^{35}$ & ngio $^{1}$ & 'know', 'find out' 20 \\
\hline & nthi ${ }^{35}$ & ndio $^{1}$ & 'find' \\
\hline & $b i^{35}$ & bhe $\mathrm{e}^{35}$ & 'get angry' \\
\hline & ndyo $^{1}$ & nkio $^{3}$ & 'come' \\
\hline & $n d i^{5}+h^{53}-b a^{35}$ & $n d i^{5}+\mathrm{hi}^{53}-\mathrm{mi}^{3}$ & 'get bad, ugly' \\
\hline \multirow[t]{7}{*}{ b. } & nchkẽ $?^{5}$ & ntyke $\tilde{e}^{12}$ & 'grow weak', 'get bored' \\
\hline & $\operatorname{tsa}^{1}$ & nda $^{1}$ & 'limp' \\
\hline & $\tilde{n} e P^{1}+k \_u e ?^{3}$ & $\tilde{\text { ne}} e^{1}+\mathrm{k}_{-} w h \mathrm{e}^{3}$ & 'want to die' \\
\hline & $\tilde{n} \mathrm{e}{ }^{1}+\mathrm{k}_{-} \mathrm{Pu}^{5}$ & $\tilde{n} e P^{1}+k_{-} w^{1}$ & 'want to drink' \\
\hline & $\mathrm{hnda}^{3}$ & $\mathrm{nda}^{3}$ & 'have an adopted child' \\
\hline & ndi $^{5}+$ hndyo $^{3}$ & ndi $^{5}+$ ndyo $^{3}$ & 'grow old (man)' \\
\hline & $\mathrm{ba}^{5}+\mathrm{kwa}^{3}$ & $\mathrm{tsa}^{5}+\mathrm{ki}^{3} \mathrm{ma}^{1}$ & 'lie down'21 \\
\hline
\end{tabular}

\subsection{Stems contrasting in tone}

More than a hundred verbs in our sample have a singular stem that contrasts in tone with the plural stem. For the instances in Table 37, the change in tone is predictable if we consider the tone of the root in the plural stem as lexical and the tone of the singular as emerging from the conflation of the lexical tone $/ 5 /$ of the reduced formative $t s i^{5}+$ with the root tone.

Table 37. Verbs with predictable tone in the singular stem

\begin{tabular}{|lll|}
\hline SG & PL & \\
\hline ts + ia $^{51}$ & nã ${ }^{1}+$ ya $^{1}$ & 'make' \\
ts $+\mathrm{kwe}^{51}$ hndyo $^{12}$ & nã ${ }^{1}+\mathrm{kwe}^{1}{ }^{1}$ hndyoo $^{12}$ & 'change' \\
ts $+\mathrm{ba}^{53}$ & nã ${ }^{1}+\mathrm{ba}^{3}$ & 'lift up' \\
ts $+\mathrm{be}^{53}$ & nã ${ }^{1}+\mathrm{be}^{3}$ & 'keep' \\
\hline
\end{tabular}

Some verbs in our sample also make the contrast between a singular and a plural stem by means of tone only. However, there is no simple form-function mapping. In other words, it is not possible to assign a function to a given tone value, e.g. tone $X$ is a marker of function $Y$. There are a number of tonal patterns involved. The variance is better understood as organized into tone classes dictated by the lexicon. Examples of the tone classes we have identified are given in Table 38 with an indication as to the number of verbs instantiating each class. The tone classes are not labeled with numbers or letters, but by the tone pairs

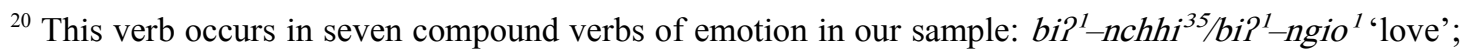

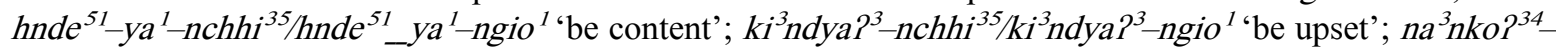

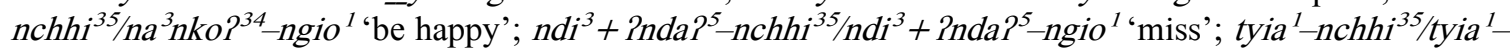

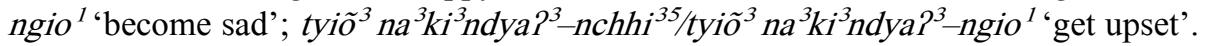

${ }^{21}$ For the verb $b a^{5}+k w a^{3}$ 'lie down' one can still see traces of how the suppletion has emerged. The plural stem $k i_{-}^{3} m a P^{1}$ surfaces alternatively as $k w a ?^{1}-$ in compounds, e.g. $b a^{5}+k w a^{3}-n g i o^{3}$ 'lie face down' with plural stem $t_{s a}{ }^{5}+\mathrm{kwa}^{1}{ }^{1}-\mathrm{ngio}^{3}$. Unstressed $/ \mathrm{ki} /$ becomes $/ \mathrm{k} /$ and $/ \mathrm{ma}^{1} /$ labializes to $/ \mathrm{wa} ?^{1} /$. One could interpret the component $k w a^{3}$ of the singular stem as originating equally from ${ }^{*} k i_{-}^{3} m a^{3}$. In such a case, the stems would only contrast in glottalization and tone.
} 
found in the singular and the plural, e.g. tone class $/ 1 \sim 3 /$ means that the stem has tone $/ 1 /$ in the singular, but tone $/ 3 /$ in the plural. ${ }^{22}$

Table 38. Tone classes in verbs whose stems only contrast in tone

\begin{tabular}{|c|c|c|c|c|}
\hline Class & SG & PL & & \# verbs \\
\hline$/ 1 \sim 3 /$ & $\begin{array}{l}\text { nd } \varepsilon^{1} \\
\text { ndui? } \\
\text { nã }{ }^{1}\end{array}$ & $\begin{array}{l}\text { nde } \varepsilon^{3} \\
\text { ndui? } \\
\text { nã } ?^{3}\end{array}$ & $\begin{array}{l}\text { 'copulate' } \\
\text { 'go out' } \\
\text { 'remove seed (cotton)', 'remove' }\end{array}$ & 8 \\
\hline$/ 3 \sim 1 /$ & $\begin{array}{l}\text { nko } \\
\text { nã }^{3} \\
\tilde{\text { ne? }}{ }^{1} \quad \mathrm{kwa}^{3}\end{array}$ & $\begin{array}{l}\text { nko } \\
\text { nã }^{1} \\
\tilde{n}^{1} ?^{1} \text { kwa? }^{1}\end{array}$ & $\begin{array}{l}\text { 'laugh' } \\
\text { 'be patient' } \\
\text { 'want to eat' }\end{array}$ & 5 \\
\hline$/ 35 \sim 1 /$ & $\begin{array}{l}\text { nd } \varepsilon^{35} \\
\text { hño } \tilde{o}^{35} \\
\tilde{n} e ?^{1} \quad k-? \tilde{o}^{35}\end{array}$ & $\begin{array}{l}\text { nde } \\
\text { hño }{ }^{1} \\
\tilde{n} e^{1}{ }^{1} \_k-? \tilde{o}^{1}\end{array}$ & $\begin{array}{l}\text { 'chew chewing gum / sugar cane' } \\
\text { 'plaster a wall' } \\
\text { 'want to exist' }\end{array}$ & 4 \\
\hline$/ 3 \sim 12 /$ & $\begin{array}{l}\left(\mathrm{ki}^{3}-\right) \mathrm{hndyu} \\
\tilde{n e}^{3} \mathrm{ri}^{3} \mathrm{ki}^{3} \mathrm{noa}^{3}\end{array}$ & $\begin{array}{l}\left(\mathrm{ki}^{3}-\right) \mathrm{hndyu}^{12} \\
\tilde{\mathrm{ne}} \mathrm{P}^{1} \mathrm{ki}^{3} \mathrm{nPoa}^{12}\end{array}$ & $\begin{array}{l}\text { 'appoint oneself' } \\
\text { 'want to heal' }\end{array}$ & 2 \\
\hline$/ 34 \sim 12 /$ & $\begin{array}{l}\text { ntyha } \\
\text { ntshó }\end{array}$ & $\begin{array}{l}\text { ntyha }^{12} \\
\text { ntshó } \\
12\end{array}$ & $\begin{array}{l}\text { 'pull' } \\
\text { 'sow again (new grain)' }\end{array}$ & 2 \\
\hline$/ 5 \sim 1 /$ & $\begin{array}{l}\mathrm{kwe}^{5} \\
\text { nkya }^{5}\end{array}$ & $\begin{array}{l}\mathrm{kwe}^{1} \\
\text { nkya }^{1}\end{array}$ & $\begin{array}{l}\text { 'dress' } \\
\text { 'give', 'hand over' }\end{array}$ & 2 \\
\hline $\mid 5 \sim 12 /$ & $\tilde{n} e^{1} \mathrm{kwe}^{5}$ & $\tilde{\text { ne}}{ }^{1} \mathrm{kwe}^{12}$ & "want to get dressed" & 1 \\
\hline$/ 53 \sim 12 /$ & $\mathrm{ka}^{53}$ & $\mathrm{kPa}^{12}$ & 'run over', 'flood' & 1 \\
\hline
\end{tabular}

All the tone classes in Table 38, except /5 12/ and /53 12/, are also attested in other verbs that present additional segmental means. The relevant figures are given in Table 39, where we correlate tone class with segmental strategy.

Table 39. Correlation between tone classes and segmental strategies

\begin{tabular}{|c|c|c|c|c|c|c|c|c|c|c|}
\hline Tone cl. & $\begin{array}{l}\text { Tone } \\
\text { only }\end{array}$ & Glottal & $\begin{array}{c}\text { Final } \\
\text { vowel }\end{array}$ & Prefix $t$ - & Prefix $n-$ & Formative & Suppletion & $\begin{array}{l}\text { Prefix } t \text { - } \\
\& \text { glottal }\end{array}$ & $\begin{array}{c}\text { Formative } \\
\& \text { suppletive }\end{array}$ & Total \\
\hline$/ 1 \sim 3 /$ & 8 & & & 25 & & 1 & 2 & & & 36 \\
\hline$/ 3 \sim 1 /$ & 5 & 16 & & 4 & 1 & 2 & & 1 & 1 & 30 \\
\hline$/ 35 \sim 1 /$ & 4 & & 5 & 1 & 1 & 1 & 2 & & & 14 \\
\hline$/ 3 \sim 12 /$ & 2 & & & 7 & & & & & & 9 \\
\hline /35 12/ & & 1 & 1 & 5 & 2 & & & & & 9 \\
\hline /34 12/ & 2 & & & 3 & & & & & & 5 \\
\hline |5 3/ & & & 2 & 3 & & & & & & 5 \\
\hline$/ 5 \sim 1 /$ & 2 & & 1 & 1 & & & 1 & & & 5 \\
\hline /53 1/ & & & & 3 & & & & & & 3 \\
\hline /5 12/ & 1 & & & & & & 1 & & & 2 \\
\hline |53 12/ & 1 & & & 1 & & & & & & 2 \\
\hline /12 34/ & & & & 1 & & & & & & 1 \\
\hline$/ 34 \sim 5 /$ & & & & & & & 1 & & & 1 \\
\hline$/ 35 \sim 3 /$ & & & & & & & 2 & & & 2 \\
\hline |53 34/ & & & & & & 1 & & & & 1 \\
\hline Total & 25 & 17 & 9 & 54 & 4 & 5 & 9 & 1 & 1 & 125 \\
\hline
\end{tabular}

\footnotetext{
${ }^{22}$ There are two missing verbs that display a tone contrast only but are disyllabic: $n d y o{ }^{1}-y ? \tilde{o}^{35}$ 'bring' (SG.OBJ) and $b e^{5}-n t y h a^{3}$ 'reach' given in Table 41 . The latter comes from S\&S and we ignore the status of its glottalization component.
} 
The figures reveal certain tendencies. For example, when a verb is specified in the lexicon as being one that changes tone, if its singular stem has tone $/ 1 /$, its plural stem will have tone $/ 3 /$. Beyond this the degree of predictability weakens. Similarly, half of the plural stems with a prefix $t$ - have a tone $/ 3 /$, the other half have either tone $/ 12 /$ or tone $/ 1 /$. Also, $90 \%$ of the verbs that have a glottalization contrast between the singular and the plural stems belong to tone class $/ 3 \sim 1 /$.

When a verb changes tone, and the verb in question has more than one syllable (commonly representing a compound, whether opaque or transparent), the default is for the lexical stem to bear the tone change. This is shown in Table 40 ( $\mathrm{a}$ and $\mathrm{b}$ ) with instances of tone class /3 1/. As pointed out in $\$ 5.5$ above, example (b) in Table 40 comes from a complementation structure involving the verb 'go'. A similar structure may be observed in example (c) where the first morph $\tilde{n} e^{1}$ is a desiderative. ${ }^{23}$

Table 40. Lexical stem with tone changes in complex verbs.

\begin{tabular}{|llll|}
\hline & SG & PL & \\
\hline a. & $\left\{\mathrm{ndo}^{3}-\mathrm{nde}^{34}\right\}$ & $\left\{\mathrm{ndo}^{1}-\mathrm{nnde}^{34}\right\}$ & 'look up' \\
b. & $\mathrm{ba}^{5}+\left\{\mathrm{kwa}^{3}-\mathrm{ngio}^{3}\right\}$ & $\mathrm{tsa}^{5}+\mathrm{ki}^{3}-\left\{\mathrm{ma}^{1}-\mathrm{ngio}^{3}\right\}$ & 'lie face down' \\
c. & $\tilde{\mathrm{ne}} \mathrm{P}^{1}-\left\{\mathrm{kwa}^{3}\right\}$ & $\tilde{\mathrm{ne}} \mathrm{P}^{1}-\left\{\mathrm{kwa}^{1}\right\}$ & 'feel like eating' \\
\hline
\end{tabular}

A few disyllabic stems in our sample, given in Table 41, undergo changes in tone involving both syllables of the lexical stem. The first two examples are transparent compounds where each stem is subject to tone changes. In light of these two examples, we also take the other instances as reflecting similar but older compounds.

Table 41. The tonal marking of disyllabic stems.

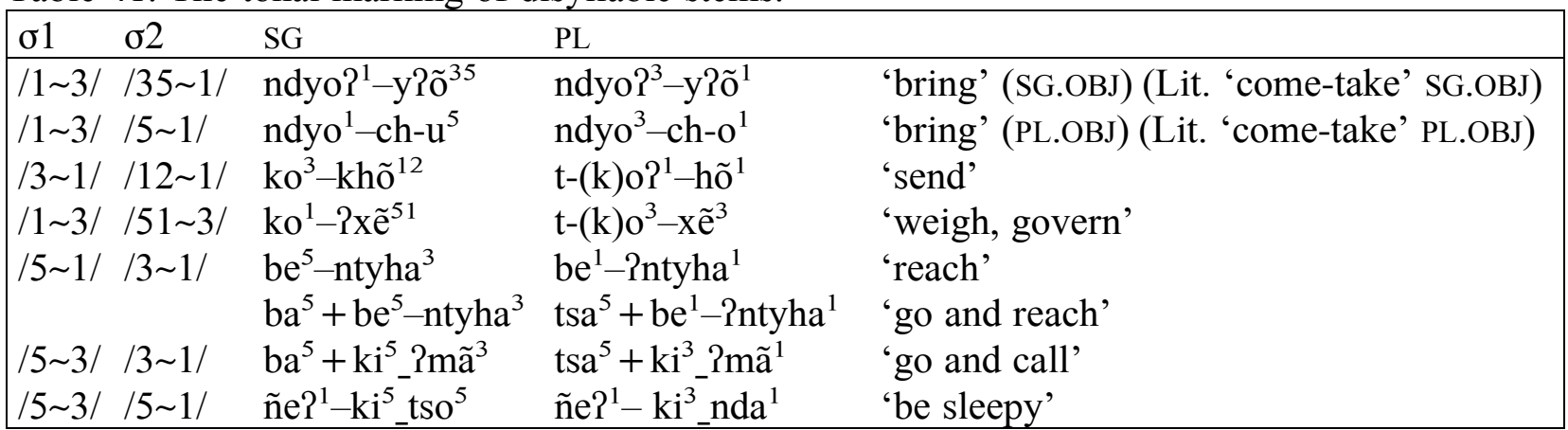

\subsection{Paradigmatic depth of the number split}

In the previous sections we have shown that the number split in Amuzgo cleaves the paradigm in two, dividing up the cells associated with singular subjects from those associated with plural subjects. We have also presented the formal mechanisms that make it possible for a verb to have the two distinct stems needed for the number split. Splits involving stems are informative about the way a paradigm is structured. When a consistent type of split applies to the paradigm of many verbs, we witness the occurrence of a characteristic property of inflection in a given system. After observing the behavior of verbs in our sample we conclude that the partition of the paradigm characterizing the number split is also a default way of partitioning a verbal paradigm in Amuzgo. To our knowledge, the verb $2 n a^{34}$ 'take over' in Table 42 is the only one in our sample that strays from such

\footnotetext{
${ }^{23}$ In contrast, the modern desiderative verb is the compound active verb $k \tilde{e}^{3}-t s 9 \tilde{o}^{3}$ 'want, desire'.
} 
partitioning, displaying instead a split in person between the forms for the 1 st person and all other persons.

Table 42. Split involving 1st person

\begin{tabular}{|c|c|c|c|}
\hline INCPL & \multicolumn{3}{|c|}{ 'take over' } \\
\hline $1 \mathrm{SG}$ & $\varnothing-$ & nha $^{3}$ & \\
\hline $2 \mathrm{SG}$ & $\varnothing-$ & $2 n a^{51}$ & $-?$ \\
\hline $3 \mathrm{SG}$ & $\varnothing-$ & ?na $a^{34}$ & \\
\hline 1PL.INCL & $\varnothing-$ & nha $^{35}$ & $\langle\tilde{a}\rangle^{5}$ \\
\hline 1PL.EXCL & $\varnothing-$ & nha $^{51}$ & \\
\hline $2 \mathrm{PL}$ & $\varnothing-$ & ?na $a^{34}$ & $=o P^{3}$ \\
\hline $3 \mathrm{PL}$ & $\varnothing-$ & ?na ${ }^{34}$ & $=\mathrm{ho}^{5}$ \\
\hline
\end{tabular}

In contrast, there are a few verbs that have more than two stems, but the third stem occurs in the singular of the 1st and 2nd persons, as shown in Table 43, adapted from Buck (2000: $450,451)$. This pattern is not found with verbs that lack a stem-based split, so we could argue that the split involving 1st and 2nd person singular is nested within the number split (for nested splits see Corbett 2015). The nested split responds to the same person syncretism we observe for the affix $\mathrm{ma}^{3}$ - used for the incompletive of the 1 st and the 2nd person singular of Class 1 verbs.

Table 43. Nested split involving 1 st and 2 nd person singular

\begin{tabular}{|c|c|c|c|c|c|}
\hline INCPL & \multicolumn{3}{|c|}{ 'drink' } & \multicolumn{2}{|l|}{ 'die' } \\
\hline $1 \mathrm{SG}$ & $\mathrm{ma}^{3}-$ & ?wa ${ }^{1}$ & & $m a^{3}-b P i\langle 0\rangle^{1}$ & \\
\hline $2 \mathrm{SG}$ & $\mathrm{ma}^{3}-$ & ?wa 51 & $-?$ & $m a^{3}-b^{2} i^{3}$ & $-?$ \\
\hline $3 \mathrm{SG}$ & $2^{5}-$ & $? u^{5}$ & & $2^{5}-\quad b e 2^{3}$ & \\
\hline 1PL.INCL & $\mathrm{ko}^{3}-$ & $\mathrm{b}\langle\varepsilon\rangle^{12}$ & $\langle\varepsilon\rangle^{5}$ & $\mathrm{ko}^{3}-\mathrm{bh}\langle\varepsilon\rangle^{34}$ & $\langle\varepsilon\rangle^{5}$ \\
\hline 1PL.EXCL & $\mathrm{ko}^{3}-$ & $\mathrm{b}\langle\varepsilon\rangle^{51}$ & & $\mathrm{ko}^{3}-\mathrm{bh}\langle\varepsilon\rangle^{51}$ & \\
\hline $2 \mathrm{PL}$ & $\mathrm{ko}^{3}-$ & $b^{1}$ & $=o ?^{3}$ & $\mathrm{ko}^{3}-\mathrm{bhe}^{3}$ & $=o ?^{3}$ \\
\hline 3PL & $\mathrm{ko}^{3}-$ & $b^{1}$ & $=h^{5}$ & $\mathrm{ko}^{3}-b h \mathrm{e}^{3}$ & $=h o^{5}$ \\
\hline
\end{tabular}

One verb in our sample has the basic number split and, in addition to this, displays three different stems for the persons in the singular. The verb is shown in Table 44, and since it is an example of a nested split we expect that there might be other verbs like it in the language.

Table 44. Nested split involving all singular persons

\begin{tabular}{|c|c|c|c|}
\hline INCPL & \multicolumn{3}{|c|}{ 'get drunk' } \\
\hline $1 \mathrm{SG}$ & Ø- & $\mathrm{ki}^{5} \mathrm{ndy}\langle\mathrm{a}\rangle^{3}$ & \\
\hline $2 \mathrm{SG}$ & $\varnothing-$ & $\mathrm{ki}^{5} \mathrm{ndyu^{3 }}$ & $-?$ \\
\hline $3 \mathrm{SG}$ & $\varnothing-$ & $\mathrm{ki}^{5} \mathrm{ndyi}{ }^{5}$ & \\
\hline 1PL.INCL & $\varnothing-$ & $\mathrm{ki}^{5} \mathrm{ndy}\langle\varepsilon\rangle^{5}$ & $\langle\varepsilon\rangle^{5}$ \\
\hline 1PL.EXCL & $\varnothing-$ & $\mathrm{ki}^{5} \mathrm{ndye}^{51}$ & \\
\hline $2 \mathrm{PL}$ & $\varnothing-$ & $\mathrm{ki}^{5} \mathrm{ndye}^{5}$ & $=o 1^{3}$ \\
\hline 3PL & $\varnothing-$ & $\mathrm{ki}^{5} \mathrm{ndye}^{5}$ & $=\mathrm{ho}^{5}$ \\
\hline
\end{tabular}

Finally, there is one verb with a fourth stem, but our expectation is that we would not find others like it in the language because it seems to push irregularity to its extreme. It is the verb $b h a^{5}$ 'go' in Table 45, which also happens to be a lexical item prone to inflectional 
idiosyncrasies cross-linguistically. Here the 1st person plural exclusive receives a distinct stem. This verb is also peculiar in having a pattern for the two stems in the singular that differs from the splits in Tables 43 and 44, but is identical to the singular portion of the paradigm in Table 42. We take this as further evidence for a greater degree of independence of the singular half of the paradigm compared with the plural half.

Table 45. The rare split of the verb $b h a^{5}$ 'go'

\begin{tabular}{|c|c|c|}
\hline INCPL & \multicolumn{2}{|l|}{ 'go' } \\
\hline $1 \mathrm{SG}$ & Ø- $\quad \mathrm{h}\langle 0\rangle^{1}$ & \\
\hline $2 \mathrm{SG}$ & bha $^{53}$ & $-?$ \\
\hline $3 \mathrm{SG}$ & Ø- bha $^{5}$ & \\
\hline 1PL.INCL & $\mathrm{ko}^{3}-2\langle 0\rangle^{5}$ & \\
\hline 1PL.EXCL & $\mathrm{ko}^{3}-\mathrm{tsa}^{51}$ & \\
\hline $2 \mathrm{PL}$ & $\mathrm{ko}^{3}-2 \mathrm{o}^{5}$ & $=o P^{3}$ \\
\hline $3 \mathrm{PL}$ & $\mathrm{ko}^{3}-2 \mathrm{o}^{5}$ & $=\mathrm{ho}^{5}$ \\
\hline
\end{tabular}

All these structures point to the existence of a deeply entrenched split in the inflection of Amuzgo verbs. In Table 46 we summarise the distinct types of stem-level splits which we have identified in SP Amuzgo (together with an indication of the number of verbs following each type). Firstly, there are verbs which display no split at stem level; the notation ' $A$ ' in Table 46 indicates the invariant stem of such verbs. Secondly, in verbs which do display a split, the first default partition is between the singular and plural forms; the notation ' $\mathrm{B}$ ' indicates the occurrence of a second stem that contrasts with the basic A-stem. Although the relation between the singular and the plural stems could be characterized synchronically as instantiating a form of suppletion, we believe that treating the plural stem as secondary is justified given the nature of the formal relation between them. We call this 'split 1a'. Once this default split happens, the paradigm can then be further partitioned with nested splits, like split $1 b$, which is relatively common, where ' $C$ ' represents a third stem. Split $1 \mathrm{c}$ reveals yet another way of splitting the singular portion of the paradigm. Finally, we consider splits $1 \mathrm{~d}$ and 2 as unique. Other ways of splitting the paradigm are not found; we give an example of an unattested split in the final column of Table 46.

Table 46. Different types of stem-level splits in SP Amuzgo verbs

\begin{tabular}{|c|c|c|c|c|c|c|c|}
\hline & & split 1a & split 1b & split 1c & split 1d & split 2 & \\
\hline & $\begin{array}{c}\text { No } \\
\text { split } \\
\text { 'smash' } \\
\text { (T. 10) }\end{array}$ & $\begin{array}{l}\text { Default } \\
\text { 'lie down' } \\
\text { (T. 1) }\end{array}$ & $\begin{array}{c}\text { Advanced } \\
\text { (same as class 1) } \\
\text { 'drink' } \\
\text { (T. 42) }\end{array}$ & $\begin{array}{c}\text { Rare } \\
\text { 'get drunk' } \\
\text { (T. 43) }\end{array}$ & $\begin{array}{l}\text { Unique } \\
\text { 'go' } \\
\text { (T. 44) }\end{array}$ & $\begin{array}{c}\text { Unique } \\
\text { (SG like split 1d) } \\
\text { 'take over' } \\
\text { (T. 41) }\end{array}$ & Unattested \\
\hline $1 \mathrm{SG}$ & A & A & $\mathrm{C}$ & $\mathrm{D}$ & $\mathrm{D}$ & B & B \\
\hline $2 \mathrm{SG}$ & A & A & $\mathrm{C}$ & $\mathrm{C}$ & A & A & B \\
\hline $3 \mathrm{SG}$ & A & A & A & $\mathrm{A}$ & A & A & $\mathrm{A}$ \\
\hline 1PL.INCL & A & B & B & B & B & B & A \\
\hline 1PL.EXCL & A & B & B & B & $\mathrm{C}$ & B & A \\
\hline $2 \mathrm{PL}$ & A & B & B & B & B & $\mathrm{A}$ & A \\
\hline $3 \mathrm{PL}$ & A & B & B & B & B & A & A \\
\hline
\end{tabular}

\section{Discussion: Making sense of the number split in Amuzgo}

We have shown that verbs in Amuzgo split their paradigm in two, partitioning the forms taking a plural subject from those taking a singular subject. We have also seen that although 
the split is not found in all verbs, in our sample of 579 verbs it nonetheless affects 393 of them. Of those, at least 91\% (360) manifest the split at stem-level. How can we make sense of this?

The crucial point is how the relation between grammatical number and grammatical person is encoded. The issue is an old one: for example in 1902 Beach Bradley published an essay on the treatment of we as the plural of $I$. Fortunately, our general knowledge of verbal inflection cross-linguistically has increased dramatically since then, and we know that the phenomenon is intricate from a typological perspective. Daniel (2013), for example, surveys different encoding possibilities regarding personal pronouns in WALS. Our interest here is in verbal indexing.

To understand the significance of the system in Amuzgo, we can start with a situation where there is a maximal disassociation between the marking of the person of the subject and the marking of the number of the subject. This situation is known to exist across languages, but it appears to be particularly common in languages of the Americas, especially in Mesoamerica. The canonical example for such a situation is given in Table 47 from Toluca Otomi, an Oto-Manguean language of Mexico distantly related to Amuzgo, where there is only one marker of plurality, the enclitic $=h \underline{u}$, adapted from Palancar (2013).

Table 47. Person and number of subject in Toluca Otomi

\begin{tabular}{|c|c|c|c|c|}
\hline \multirow[b]{2}{*}{ INCPL.REALIS } & \multicolumn{4}{|c|}{ 'walk' } \\
\hline & Person & TAM & Stem & Number \\
\hline $1 \mathrm{SG}$ & d- & rá $=$ & 'yo & - \\
\hline $2 \mathrm{SG}$ & g- & rá $=$ & 'yo & - \\
\hline $3 \mathrm{SG}$ & $\varnothing-$ & $\mathrm{ra}=$ & 'yo & \\
\hline 1PL & d- & rá $=$ & 'yo & $=h \underline{u}$ \\
\hline $2 \mathrm{PL}$ & g- & rá $=$ & 'yo & $=h \underline{u}$ \\
\hline 3PL(HUM.DEF) & $\varnothing-$ & $\mathrm{ra}=$ & 'yo & $=h \underline{u}$ \\
\hline
\end{tabular}

The crucial thing about the system in Toluca Otomi is that the marking for the person of the subject remains completely independent from the expression of the plurality of the individuals or entities involved (the less marked option is interpreted as singular by default), and as a consequence person markers convey just person, and number markers number. In other systems, we witness how specific markers for a given plural person can co-occur with the invariant marking of number. This is observed in the different subparadigms in Table 48 from Tseltal, a Mayan language of Mexico, adapted from Polian (2013).

Table 48. Person and number of subject in Tseltal

\begin{tabular}{|c|c|c|c|c|c|c|c|c|c|}
\hline \multirow[b]{2}{*}{ CPL } & \multirow[b]{2}{*}{ Stem } & \multicolumn{3}{|c|}{ 'open' (intr) } & \multicolumn{5}{|c|}{ 'grab’ (tr) } \\
\hline & & Person/S & Number & INCPL & AUX & Person/A & Stem & Person & Number \\
\hline $1 \mathrm{SG}$ & k'ajin & -on & - & $1 \mathrm{SG}>3$ & ya & j- & tsak & & - \\
\hline $2 \mathrm{SG}$ & $k^{\prime}$ ajin & -at & - & $2 \mathrm{SG}>3$ & ya & $a-$ & tsak & & - \\
\hline $3 \mathrm{SG}$ & k'ajin & $-\varnothing$ & & $3 \mathrm{SG}>3$ & ya & S- & tsak & & \\
\hline $1 \mathrm{PL}$ & k'ajin & $-o t$ & $-\mathrm{ik}$ & $1 \mathrm{PL}>3$ & ya & j- & tsak & $-\mathrm{t}$ & $-\mathrm{ik}$ \\
\hline 2PL & $k^{\prime}$ ajin & -at & $-\mathrm{ik}$ & $2 \mathrm{PL}>3$ & ya & $a-$ & tsak & & $-i k$ \\
\hline $3 \mathrm{PL}$ & k'ajin & $-\varnothing$ & $-\mathrm{ik}$ & $3 \mathrm{PL}>3$ & ya & S- & tsak & & $-\mathrm{ik}$ \\
\hline
\end{tabular}


The plurality of the person of the subject is indicated in Tseltal by the suffix $-i k$. In this, it is the same type of system that we observe in Toluca Otomi in Table 47, but in Tseltal, for the marking of 1st person plural, we have the specific marker -ot for the completive of an intransitive verb, and the suffix $-t$ for the incompletive of a transitive. ${ }^{24}$ This is proof that, at least in this specific case, the language is treating 1 st person plural as a class.

A related system is also found in Turkish as shown in Table 49, from Göksel and Kerslake (2005). Here we observe a different marker for plural associated to person: $-u z$ is for speech-act participants, but -lar is for the 3rd person, and is also the marker used for plurals of nouns. Notice that in Turkish, 1st person plural is also treated differently from the singular, this time by elision of the person marker.

Table 49. Person and number of subject in Turkish

\begin{tabular}{|c|c|c|c|c|}
\hline \multirow[b]{2}{*}{ PRS.CONT } & \multicolumn{4}{|c|}{ 'open' } \\
\hline & Stem & TAM & Person & Number \\
\hline $1 \mathrm{SG}$ & $\mathrm{aç}$ & -1yor & -um & $\ldots$ \\
\hline $2 \mathrm{SG}$ & $\mathrm{aç}$ & -1yor & -sun & - \\
\hline $3 \mathrm{SG}$ & aç & -1yor & $-\varnothing$ & \\
\hline 1PL & aç & -1yor & _ & $-\mathrm{uz}$ \\
\hline $2 \mathrm{PL}$ & aç & -1yor & -sun & $-\mathrm{uz}$ \\
\hline $3 \mathrm{PL}$ & $\mathrm{aç}$ & -1yor & $-\varnothing$ & -lar \\
\hline
\end{tabular}

In systems like these, the marker for number is canonically agglutinative (Plank 1999). Specifically, it has little allomorphy, and where allomorphy does occur it is conditioned by the phonology (i.e. it is normally just one invariant affix or a clitic); its application commonly responds to a transparent morphosyntactic rule (i.e. when the syntax requires it, speakers use it with all verbs); it has uncomplicated morphotactics; and syntactically it occurs at the outer periphery of the stem. ${ }^{25}$ As for scope, if the language allows for head-marked indexing of objects, the same number markers may also be used to indicate the plural value of the object, although there may be specific collocation restrictions. This is illustrated in Table 50 in Tseltal, from Polian (2013).

\footnotetext{
${ }^{24}$ One referee suggested to us that $-o t$ - $t$ could equally be interpreted as operating within the realm of number. Our position is that this morphology is conflating person (1st person) and number (plural), signalling an emergent class of ' 1 st person plural'.

${ }^{25}$ An apparent counter-example to this is found in Piaroa, a South American language of the Saliban family, as shown in (i). Data from Mosonyosi (2000), adapted from Rosés Labrada (2015) and Jorge E. Rosés (p.c.). The rarity of this system may be related to its origin as Rosés Labrada (2015) shows that the person suffixes have emerged from a grammaticalized inflected copula.
}

\begin{tabular}{llll|} 
(i) & 'work' & \\
PRS & Stem & Number & Person \\
\cline { 2 - 4 } 1SG.M & aditi & - & -sæ \\
2SG.M & aditi & - & - hæ \\
3SG.M & aditi & - & $-\varnothing$ \\
\cline { 2 - 4 } 1PL & adit(i) & -æti & -sæ \\
2PL & adit(i) & -æti & -hæ \\
3PL & adit(i) & -æti & $-\varnothing$ \\
\hline
\end{tabular}


Table 50. Person and number of object in Tseltal

\begin{tabular}{|c|c|c|c|c|c|}
\hline \multirow[b]{2}{*}{ CPL } & \multicolumn{5}{|c|}{ 'help' (tr) } \\
\hline & AUX & Person/A & Stem & Person/O & Number \\
\hline $3>1 \mathrm{SG}$ & la & s- & koltay & -on & - \\
\hline $3>2 \mathrm{SG}$ & la & S- & koltay & -at & - \\
\hline $3>3 \mathrm{SG}$ & la & S- & koltay & $-\varnothing$ & \\
\hline $3>1 \mathrm{PL}$ & la & s- & koltay & - ot & $-i k$ \\
\hline $3>2 \mathrm{PL}$ & la & S- & koltay & $-a t$ & $-\mathrm{ik}$ \\
\hline $3>3 \mathrm{PL}$ & la & S- & koltay & $-\varnothing$ & -ik \\
\hline
\end{tabular}

Amuzgo is similar to systems like these in also having the encoding of the number of the subject independent from that of the person of subject, but it differs from them in at least four main respects:

i) A lexeme may manifest a split in its paradigm principally by having two different stems specified, one for each portion of the split. The stems synchronically hold a suppletive relation to each other, i.e. they are provided by the lexicon and are learned independently.

ii) The two stems are used as indexes for the number of the subject, i.e. S/A, and never for the number of the object.

iii) Not all verbs have this split paradigm, although the majority do. While this suggests that the default for a verb is to belong to the class that has the split, speakers still need to remember which verbs do not have the split.

iv) Besides the number split, the verbal inflection of Amuzgo has a fully fledged paradigm of person-number markers, i.e. the information about the person of the subject and the information about the number of such persons is conflated in the grammatical exponence.

Although property (iv) makes the number split seem redundant from a morphosyntactic point of view, stem choice is also commonly taken as occurring at a deep level in the building of a given inflectional form in a paradigm (at least in Word and Paradigm models such as Paradigm Function Morphology, Stump 2001). This view has consequences for the way in which we understand the system behind the number split in Amuzgo in relation to the system in languages like Toluca Otomi or Tseltal. It suggests that when producing a given inflectional form to describe a certain state of affairs, in the derivation one needs to attend first to the number of the subject of the verb to retrieve the right stem of that verbal lexeme. This appears to come at a stage that is necessarily prior to the selection of person marking, which is affixal and for the most part clitic-like.

On the other hand, we have seen in $\S 4$ that many verbs in Amuzgo manifest the number split at the level of TAM marking in the incompletive. Consider the incompletive subparadigm of the intransitive inactive verb tyion ${ }^{35}$ 'exert one's force' in Table 51, where the grammatical information written in a continuous line applies to the prefixes. 
Table 51. Person and number of subject plus TAM in SP Amuzgo

\begin{tabular}{|c|c|c|c|c|}
\hline \multirow[b]{2}{*}{ INCPL } & & \multicolumn{3}{|c|}{ 'exert one's force' } \\
\hline & & & Stem & PRO \\
\hline $\begin{array}{l}1 \mathrm{SG} \\
2 \mathrm{SG} \\
3 \mathrm{SG}\end{array}$ & Person $(1,2,3) \&$ Number (SG) of S/A [\& Aspect (INCPL)] & $\begin{array}{l}\mathrm{ma}^{3}- \\
\mathrm{ma}^{3}- \\
\mathrm{P}^{5}-\end{array}$ & $\begin{array}{l}\text { tyion } 2^{35} \\
\text { tyion } 2^{35} \\
\text { tyion } 2^{35}\end{array}$ & $\begin{array}{l}=\mathrm{ha}^{3} \\
=\mathrm{Pu}^{3} \\
=\tilde{\mathrm{e}}^{5}\end{array}$ \\
\hline $\begin{array}{l}\text { 1PL.INCL } \\
\text { 1PL.EXCL } \\
\text { 2PL } \\
\text { 3PL }\end{array}$ & Number (PL) of S/A [\& Aspect (INCPL)] & $\begin{array}{l}\mathrm{ko}^{3}- \\
\mathrm{ko}^{3}- \\
\mathrm{ko}^{3}- \\
\mathrm{ko}^{3}-\end{array}$ & $\begin{array}{l}\text { tyion } 2^{35} \\
\text { tyion }^{35} \\
\text { tyion? }{ }^{35} \\
\text { tyion? }^{35}\end{array}$ & $\begin{array}{l}=\mathrm{ha}^{5} \mathrm{a}^{5} \\
=\mathrm{ha}^{51} \\
=2 \mathrm{o}^{3} \\
=\tilde{\mathrm{e}}^{3}\end{array}$ \\
\hline
\end{tabular}

The subparadigm in Table 51 is split in two at the affixal level. The affixes in the plural do not convey information about the person of the subject. The person of the subject for this particular section of the paradigm is retrieved from the contrasts present in the pronominal set. The affix is cumulative in that it also conveys information about the incompletive aspect. A similar type of TAM-based split is found in Old English in the variety of Standard West Saxon. For this purpose, consider the different subparadigms of the verb bindan 'bind' in Table 52, adapted from Sweet (1886: 22). The grammatical information written in a continuous line applies to the suffixes (there are additional stem alternation patterns which are not discussed here).

Table 52. Person and number of subject plus TAM in Standard West Saxon.

\begin{tabular}{|c|c|c|c|c|}
\hline PRS.IND & PRO & $\begin{array}{l}\text { 'bind' } \\
\text { Stem }\end{array}$ & & \\
\hline $1 \mathrm{SG}$ & $\mathrm{ic}$ & bind & $-\mathrm{e}$ & \\
\hline $2 \mathrm{SG}$ & ðū & bind & -est & Person $(1,2,3) \&$ Number (SG) of S/A [\& Tense (PRS) \& Mood (IND)] \\
\hline $3 \mathrm{SG}$ & hè & bind & -eð & \\
\hline $1 \mathrm{PL}$ & $\mathrm{we}$ & bind & $-\mathrm{a}$ & \\
\hline $2 \mathrm{PL}$ & $\dot{\mathrm{g}} \overline{\mathrm{e}}$ & bind & $-\mathrm{a}$ & Number (PL) of S/A [\& Tense (PRS) \& Mood (IND)] \\
\hline 3PL & hīe & bind & $-\mathrm{a}$ & \\
\hline \multicolumn{5}{|l|}{ PST.IND } \\
\hline \multirow{6}{*}{$\begin{array}{l}1 \mathrm{SG} \\
2 \mathrm{SG} \\
3 \mathrm{SG} . \mathrm{M} \\
1 \mathrm{PL} \\
2 \mathrm{PL} \\
3 \mathrm{PL} \\
\end{array}$} & $\mathrm{ic}$ & band & $-\varnothing$ & \multirow{3}{*}{ Person $(1,2,3) \&$ Number (SG) of S/A [\& Tense (PST) \& Mood (IND)] } \\
\hline & ðū & bund & $-e$ & \\
\hline & hè & band & $-\varnothing$ & \\
\hline & $w \bar{e}$ & bund & -on & \multirow{3}{*}{ Number (PL) of S/A [\& Tense (PST) \& Mood (IND)] } \\
\hline & $\dot{\mathrm{g}} \overline{\mathrm{e}}$ & bund & -on & \\
\hline & hīe & bund & -on & \\
\hline \multicolumn{5}{|c|}{ PRS.SUBJV } \\
\hline \multirow{6}{*}{$\begin{array}{l}1 \mathrm{SG} \\
2 \mathrm{SG} \\
3 \mathrm{SG} . \mathrm{M} \\
1 \mathrm{PL} \\
2 \mathrm{PL} \\
3 \mathrm{PL} \\
\end{array}$} & $\mathrm{ic}$ & bind & $-\mathrm{e}$ & \multirow{3}{*}{ Number (SG) of S/A [\& Tense (PRS) \& Mood (SUBJV)] } \\
\hline & ðū & bind & $-\mathrm{e}$ & \\
\hline & hē & bind & $-\mathrm{e}$ & \\
\hline & $\mathrm{we}$ & bind & -en & \multirow{3}{*}{ Number (PL) of S/A [Mood (SUBJV)] } \\
\hline & $\dot{\mathrm{g}} \overline{\mathrm{e}}$ & bind & -en & \\
\hline & hīe & bind & -en & \\
\hline
\end{tabular}




\begin{tabular}{|c|c|c|c|c|}
\hline \multicolumn{5}{|c|}{ PST.SUBJV } \\
\hline $1 \mathrm{SG}$ & $\mathrm{ic}$ & bund & $-\mathrm{e}$ & \multirow{3}{*}{ Number (SG) of S/A [\& Tense (PRS) \& Mood (SUBJV)] } \\
\hline $2 \mathrm{SG}$ & & bund & $-e$ & \\
\hline 3SG.M & hē & bund & $-e$ & \\
\hline $1 \mathrm{PL}$ & wē & bund & -en & \multirow{3}{*}{ Number (PL) of S/A [Mood (SUBJV)] } \\
\hline 2PL & $\dot{\mathrm{g}} \overline{\mathrm{e}}$ & bund & -en & \\
\hline 3PL & hīe & bund & -en & \\
\hline
\end{tabular}

We can see in Table 52 that the pattern is similar to the Amuzgo case in Table 51, with the notable difference that suffixes in West Saxon do not convey information about person in the subjunctive mood. But despite similarities, what makes Amuzgo typologically remarkable is not only that the TAM-based split can co-occur with a stem-based split, as illustrated in Table 53, but that this co-occurrence is the default case.

Table 53. Person and number of subject plus TAM and stem-split in SP Amuzgo

\begin{tabular}{|c|c|c|c|c|}
\hline & \multicolumn{3}{|c|}{ 'lie down' } \\
\hline INCPL & & & Stem & PRO \\
\hline $1 \mathrm{SG}$ & & $\mathrm{ma}^{3}-$ & $\mathrm{me}^{1}$ & $=\mathrm{ha}^{3}$ \\
\hline $2 \mathrm{SG}$ & Person $(1,2,3) \&$ Number $(\mathrm{SG})$ of S/A [\& Aspect (INCPL)] & $\mathrm{ma}^{3}-$ & me $?^{1}$ & $=2 u^{3}$ \\
\hline $3 \mathrm{SG}$ & & $2^{5}-$ & me? ${ }^{1}$ & $=\tilde{\mathrm{e}}^{5}$ \\
\hline 1PL.INCL & & $\mathrm{ko}^{3}-$ & toẽ $?^{3}$ & $=\mathrm{ha}^{5} \mathrm{a}^{5}$ \\
\hline 1PL.EXCL & Number (PL) of S/A [\& Aspect (INCPL)] & $\mathrm{ko}^{3}-$ & toẽ $?^{3}$ & $=\mathrm{ha}^{51}$ \\
\hline 2PL & & $\mathrm{ko}^{3}-$ & toẽ $?^{3}$ & $=? \mathrm{O}^{3}$ \\
\hline 3PL & & $\mathrm{ko}^{3}-$ & toe $\mathrm{P}^{3}$ & $=\tilde{\mathrm{e}}^{3}$ \\
\hline
\end{tabular}

Finally, it is worth comparing Amuzgo to other Oto-Manguean languages to understand how it relates to other systems in this phylum. We have seen the system of Toluca Otomi in Table 47, but to the best of our knowledge the most similar number split to Amuzgo is found in distantly related Chichimec (Oto-Pamean), ${ }^{26}$ although there the phenomenon appears to be restricted to only a few verbs.

The verbal inflection of Chichimec abounds in stem alternation patterns. For instance, based on Angulo (1933), Palancar and Avelino (to appear) propose the existence of 14 such patterns. One of the patterns reveals a similar type of stem-based number split that we find in Amuzgo. This is shown in Table 54a with the verb ndü 'go'. In a sample of 168 verbs, only 18 behave like this $(10 \%)$. The remaining verbs follow other patterns. One pattern is the absence of stem alternations (Table 54b) instantiated by 30 verbs, while the stem alternation pattern in Table 54c is found in 36 verbs which have a different stem for 3rd person plural. Also, verbs fall into different classes depending on the prefix sets they select. As it happens, the three verbs in Table 54 all belong to different prefix classes.

Interestingly, like in Toluca Otomi the prefix set in Table 54c does not encode number of the subject. Number of subject - dual and plural (as well as clusivity) - is conveyed by means of suffixes. (Data adapted from Angulo 1933: 165, 174-175).

\footnotetext{
${ }^{26}$ Within Oto-Manguean, a related system is also found in Tlapanec. According to Suárez (1983), Tlapanec verbs fall into many tone classes according to their inflection, but for many such classes involving intransitive verbs all plural persons receive the same tone (the tone value in question may vary depending on class). However, as this happens with intransitive verbs only, the case at hand involves a plural S, not an A.
} 
Table 54. Person and number of subject in Chichimec

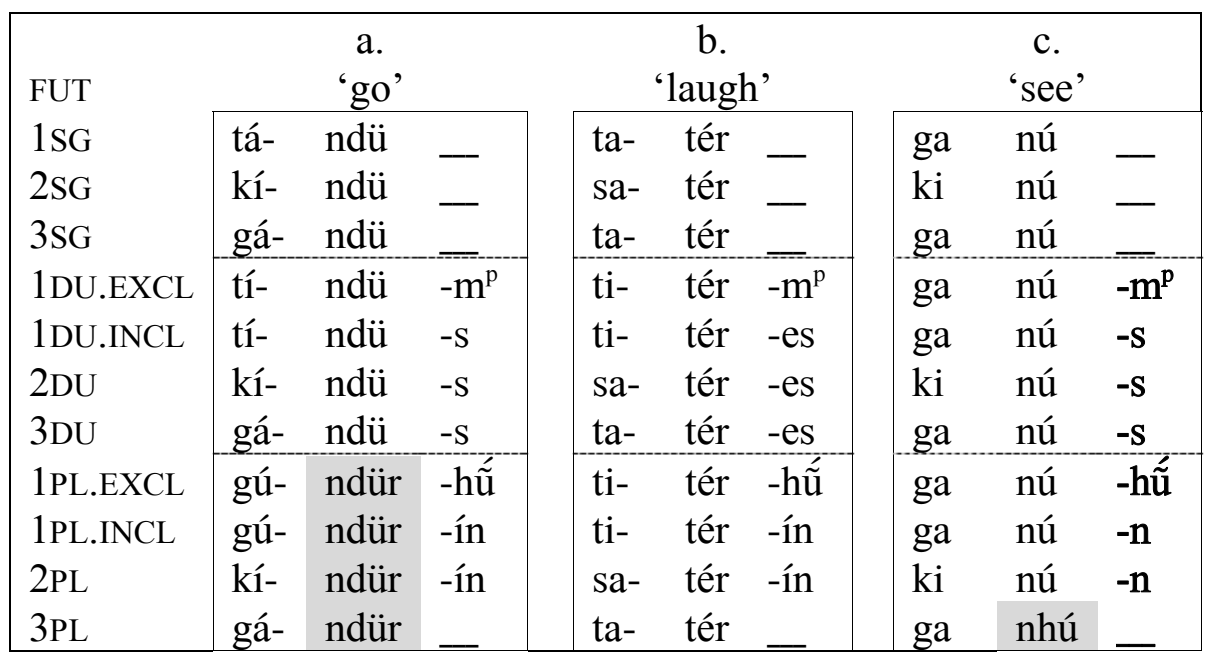

\section{Conclusion}

In this paper, we have shown that many verbs in SP Amuzgo have an inflectional split that responds to the number of the subject. While the study has been focused on the language of San Pedro Amuzgos, the existing grammatical materials of Xochistlahuaca Amuzgo (Buck 2012) reveal a very similar inflectional system in all respects, both formally and distributionally. ${ }^{27}$ Although a comparison of the two varieties to determine the scope of variation within the family must be left to future research, we can safely conclude that the number split is a trait of Amuzgo.

For the most part, the number split is manifested at stem-level. This means that for the building of inflectional forms for the different persons of the subject, one stem is used for the persons of the singular, while another is used for the plural. We have also seen that the formal relation between the singular and the plural stems suggests that the singular one is more basic. But the mechanisms deriving plural stems are no longer productive, a fact that, together with the high degree of lexical specificity (i.e. irregularity) that we observe, justifies treating the stems as being in a suppletive relation to each other.

Suppletion in turn suggests that for a large portion of the verbal lexicon, speakers have to learn at least two independent stems (there are also verbs with more than two stems) so that the syntax can select either a singular or plural one. In this respect, Amuzgo is typologically remarkable. We know of other languages with verbal number (e.g. Ainu, Yaqui, Hiw, Samoan, etc.), but in those languages the phenomenon is very different: it is not part of the inflection; it involves a reduced number of lexical pairs; and the agreement pattern is with the number of the $\mathrm{S}$ and the $\mathrm{O}$ arguments. Similarly, while inflectional systems involving a paradigmatic contrast between two (or more) stems are also attested, they often realize aspectual distinctions (e.g. Greek, Farsi, etc.). To the best of our knowledge, the number split as it occurs in Amuzgo has not been reported to occur in any other language, or at least not to the extent that it is manifested in Amuzgo. Because of this, it deserves our attention.

\footnotetext{
${ }^{27}$ For example, for the cognate transitive verb 'cut' both languages have very similar forms: SP Amuzgo 3SG.INCPL $P^{5}-[?] w a^{1} V S$. Xoch. Amuzgo 3SG.INCPL $m a^{3}-k$ ? $w a^{1}$ (with the prefix $m a^{3}-$ for all singular persons in the incompletive); and SP Amuzgo 3PL.INCPL $k o^{3}-t-{ }^{3} w a^{3} v s$. Xoch. Amuzgo 3PL.INCPL $k w i^{3}-t-[k]$ ? $w a^{3}$. There are many verbs like this displaying very similar behavior.
} 
The Oto-Manguean languages of Mexico have challenging morphologies. Amuzgo is no exception. In fact, when other aspects of its inflection are taken into account, such as TAM classes, glottalization classes and tone classes, we can truly appreciate the extremely complex morphological system of this small language family within Oto-Manguean.

Our final words here should be of acknowledgment. Without the commitment of native linguist Fermín Tapia, it would have taken linguistics much longer to discover a unique language to expand our understanding of the treatment of number in the verbal domain. This is good news, because for a threatened language like San Pedro Amuzgo, it comes at the right time.

\section{References}

de Angulo, Jaime. 1933. The Chichimeco Language (Central Mexico). International Journal of American Linguistics 7(3/4): 152-194.

Apostol Polanco. Jair. 2014. Clases flexivas verbales en el amuzgo de Xochistlahuaca, Guerrero. Unpublished MA Dissertation at CIESAS.

Beach Bradley, Cornelius. 1902. "We" the plural of "I"? Modern Language Notes 17-1: 1-3. The Johns Hopkins University Press.

Buck, Marjorie. J. 2012. Gramática del amuzgo de Xochistlahuaca. MS

------2000. Gramática amuzga de San Pedro Amuzgos, Oaxaca, in C. Stewart and R. Stewart (eds.), Diccionario amuzgo de San Pedro Amuzgos, Oaxaca, pp. 361-480. Mexico City: SIL Mexico.

Cabredo Hofherr, Patricia. 2010. Verbal plurality and event plurality. MS. Accessible at $<$ https://www.eva.mpg.de/lingua/conference/2010_summerschool/pdf/course_materials /Cabredo2010plV.pdf >

Cabredo Hofherr, Patricia and Brenda Laca. 2012. Introduction: Event plurality, verbal plurality and distributivity. In Patricia Cabredo Hofherr and Brenda Laca (eds.), Verbal plurality and distributivity, 1-24. Berlin: De Gruyter.

Caron, Bernard. 2012. Hausa grammatical sketch. MS accessible at https://halshs.archives-ouvertes.fr/halshs-00647533v3.

Corbett, Greville. 2000. Number. Cambridge: Cambridge University Press.

------2015. Morphosyntactic complexity: A typology of lexical splits. Language 91: 145193.

Daniel. Michael. 2013. Pluralitv in independent personal pronouns. in Matthew Dryer and Martin Haspelmath (eds. ). The World Atlas of Lanquage Structures Online. Leipzig: Max Planck Institute for Evolutionary Anthropology. (Available online at http://wals.info/chapter/35, Accessed on 2015-07-01.)

Donohue, Mark and Søren Wichmann (eds.). 2008. The typology of semantic alignment. Oxford: Oxford University Press.

Eulenberg, John B. 1971. Conjunction reduction and reduplication in African language, in Chin-Wu Kim and Herbert Stahlke (eds.), Papers in African Linguistics (Current Inquiry into Language and Linguistics 1), 71-80. Edmonton: Linguistic Research.

François, Alexandre. 2009. Verbal number and suppletion in Hiw. Paper read at the Eleventh International Conference on Austronesian Linguistics, Paris.

Gillon, Carrie and Robert Mailhammer. 2015. Reanalyzing the Morphology and Semantics of Verbal Plural Marking in Quechan. International Journal of American Linguistics 81-4: 573-593.

Göksel, Aslı and Celia Kerslake. 2005. Turkish: A comprehensive grammar. London: Routledge. 
Henderson, Robert. 2012. Ways of pluralizing events. Unpublished PhD Dissertation at University of California at Santa Cruz.

Jamieson, Carole Ann. 1982. Conflated Subsystems Marking Person and Aspect in Chiquihuitlán Mazatec Verbs . International Journal of American Linguistics 48(2): 139-167.

Kim, Yuni. In press. Tonal overwriting and inflectional exponence in Amuzgo, in Enrique L. Palancar and Jean Léo Léonard (eds.), Tone and inflection: New facts and new perspectives. Berlin: De Gruyter Mouton. (To appear Feb. 2016)

----- To appear. A morphophonological parameter hierarchy for Amuzgo glottalization classes, in Enrique L. Palancar, Matthew Baerman and Timothy Feist (eds.), Inflectional complexity and verb classes: $A$ view from the Oto-Manguean languages of Mexico.

Maiden, Martin. 2005. Morphological autonomy and diachrony. Yearbook of Morphology 2004, 137-175.

Mithun. Marianne. 1991. Active/Agentive case marking and its motivations. Language 67: 510-546.

------ 2001. The languages of Native North America. Cambridge: Cambridge University Press.

Mosonyi, Esteban Emilio. 2000. Elementos gramaticales del idioma piaroa, In María Stella González de Pérez and María Luisa Rodríguez (eds.), Lenguas indígenas de Colombia: Una visión descriptiva, 657-668. Santafé de Bogotá: Instituto Caro y Cuervo.

Newman, Paul. 1980. The Classification of Chadic within Afroasiatic. Leiden: Leiden University Press.

Palancar, Enrique L. 2013. The evolution of number in Otomi: The many faces of the dual. Studies in Language 37-1: 94-142.

Palancar, Enrique L. and Heriberto Avelino. To appear. Inflectional complexity and verb classes in Chichimec, in Enrique L. Palancar, Matthew Baerman and Timothy Feist (eds.), Inflectional complexity and verb classes: $A$ view from the Oto-Manguean languages of Mexico.

Plank, Frans. 1999. Split morphology: How agglutination and flexion mix. Linguistic Typology 3, 279-340.

Polian, Gilles. 2013. Gramática del tseltal de Oxchuk. Mexico City: CIESAS.

Rosés Labrada, Jorge E. 2015. The Mako language: Vitality, grammar and classification. Unpublished PhD Dissertation at the The University of Western Ontario and Université Lumière-Lyon 2.

Rupp, Jaime and Nadine de Rupp. 1996. Diccionario chinanteco de San Juan Lealao Oaxaca. [Serie de Vocabularios y Diccionarios Indígenas "Mario Silva y Aceves" 35]. Mexico City: Instituto Lingüístico de Verano.

Smith-Stark, Thomas C. and Fermín Tapia García. 1986. The active-static nature of Amuzgo (Otomanguean). Paper presented at the Annual meeting of the Linguistic Society of America, New York.

Smith-Stark, Thomas C. and Fermín Tapia García. 2002. El amuzgo como lengua activa. In Paulette Levy (ed.), Del cora al maya yucateco: Estudios lingüísticos sobre algunas lenguas mexicanas, 81-129. Mexico City: Universidad Nacional Autónoma de México.

Stewart, Cloyd and Ruth Stewart. 2000. Diccionario amuzgo de San Pedro Amuzgos, Oaxaca. Mexico City: SIL Mexico.

Stump, Gregory T. 2001. Inflectional morphology. Cambridge: Cambridge University Press. 
2006. Heteroclisis and Paradigm Linkage. Language 82(2). 279-322.

Suárez. Jorge A. 1983. La lengua tlapaneca de Malinaltepec. Mexico Citv: Instituto de Investigaciones Filológicas, Universidad Nacional Autónoma de México.

Sweet, Henry. 1886. An Anglo-Saxon premier, with grammar, notes and glossary [3rd Editionl. Oxford: Clarendon Press.

Tamura. Suzuko. 1988/2000. The Ainu Language. Tokyo: Sanseido. [Translated from Japanese into English by Sanseido Co. Ltd1.

Valenzuela. Pilar M. 1997. Basic verb tvpes and argument structures in Shipibo-Conibo. Unpublished PhD. Dissertation at the University of Oregon. 
Table 17. Inflectional classes of verbs in SP Amuzgo for the marking of the incompletive.

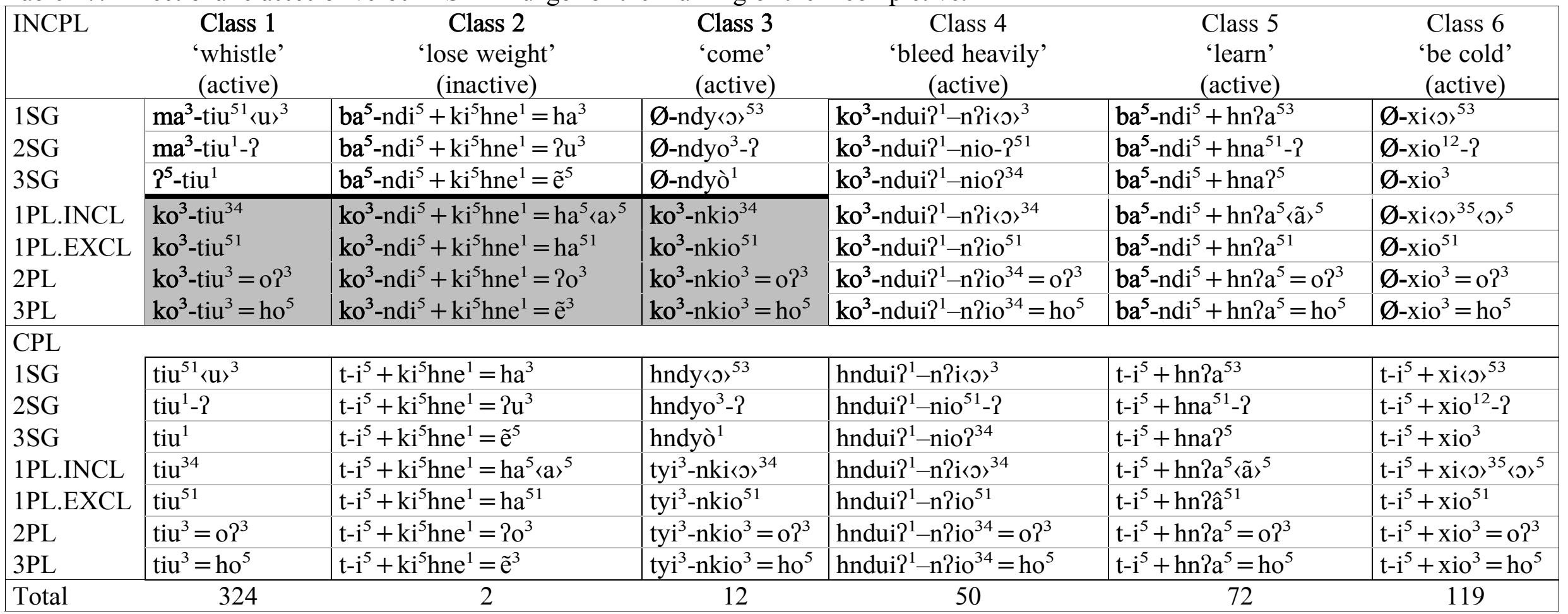

